REVISTA DE DERECHO UNED, NÚM. 7, 2010

\title{
DERECHOS DE LA CIUDADANÍA ESPAÑOLA EN EL EXTERIOR*
}

\author{
Juan Manuel Goig Martínez \\ Profesor Titular de Derecho Constitucional. Departamento de Derecho \\ Político. Facultad de Derecho. UNED
}

Resumen: La emigración española ha constituido un fenómeno constante. La legislación española sobre emigración ha evolucionado paralelamente a la evolución del proceso. La Constitución de 1978 supuso un cambio en el tratamiento de los emigrantes españoles, imponiendo a los poderes públicos su protección y el establecimiento de una política integral de retorno. La Ley 40/2006, de 14 de diciembre, del Estatuto de la ciudadanía española en el exterior establece el marco jurídico y los instrumentos básicos para garantizar a la ciudadanía española en el exterior el ejercicio de los derechos y deberes constitucionales, en términos de igualdad con los españoles residentes en el territorio nacional.

Abstract: The Spanish emigration has constituted a constant phenomenon. The Spanish legislation on emigration has evolved parallel to the evolution of the process. The Constitution of 1978 supposed a change in the treatment of the Spanish emigrants, imposing to the public power his (her,your) protection and the establishment of an integral politics (policy) of return. The Law 40/2006, of December 14, of the Statute of the Spanish citizenship in the exterior establishes the juridical frame and the basic instruments to guarantee to the Spanish citizenship in the exterior the exercise (fiscal year) of the rights and constitutional duties (homework), in terms (ends) of equality with the resident Spanish in the national territory

* La elaboración de este artículo se ha realizado en el marco del Proyecto de investigación "Constitución y globalización: transformaciones del Estado constitucional y constitucionalización de espacios supranacionales», n DER2009-10375 (Subprograma JURI) financiado por el Ministerio de Educación. 
Palabras clave: Emigración, retorno, legislación, políticas públicas.

Key words: Emigration, return, legislation, public policies.

Sumario: 1. Introducción.-2. El tratamiento legislativo de la emigración española.-3. El tratamiento constitucional de los derechos de los ciudadanos españoles en el extranjero y la legislación de desarrollo.-4. El estatuto de la ciudadanía española en el exterior;-4.1. Ámbito de reconocimiento de derechos:-4.1.1. Derechos políticos y de participación: -4.1.1.1. Derecho a ser elector y elegible,-4.1.1.2. Derecho de asociación, 4.1.1.3. Derecho a la participación en los órganos consultivos de la emigración.-4.1.2. Derechos sociales y prestaciones:-4.1.2.1. Derecho a la educación.-4 .1.2.2. Derechos sociales y de prestación.-5. Política integral en materia de retorno. ¿El derecho al retorno?

\section{INTRODUCCIÓN.}

La historia de la humanidad muestra que el desplazamiento de poblaciones como consecuencia de guerras, persecuciones políticas o religiosas, hambrunas, comercio de esclavos, conquistas, cautiverios o colonización, ha sido una constante a lo largo de los siglos.

Actualmente España es tierra de acogida; sin embargo, hasta la década de los noventa ha sido un país de emigración. A lo largo de la historia se han ido sucediendo y, en ocasiones, superponiendo distintos movimientos migratorios que respondían a causas sociodemográficas, económicas y/o ideológicas ${ }^{1}$.

La emigración española ha constituido un fenómeno constante, que se acentuó desde la segunda mitad del siglo XIX hasta más allá de mediados del siglo XX.

Las grandes transformaciones demográficas, económicas y sociales que tuvieron lugar en el continente europeo entre 1840 y 1930 afectaron a millones de personas. Hombres y mujeres de todos los rincones de Europa protagonizaron un gran movimiento migratorio hacia el otro lado del Atlántico. La emigración española hacia América Central y del Sur formó parte de esta epopeya europea, y alrededor de 3 millones y medio dejaron el país con destino a América, en lo que vino a denominarse la «emigración en masa».

${ }^{1}$ Un importante estudio sobre la migración española puede verse en GARCÍA LÓPEZ, J.R.- Las remesas de los emigrantes españoles en América: siglos XIX y XX. Júcar, 1992, y en MÉNDEZ VENEGAS, E.- Emigrantes a América (s. XVI-XVIII). Mérida, Regional de Extremadura. 1995 
Este proceso migratorio se produce principalmente, por causas económicas, ya que a comienzos del siglo XX, España era un país de economía agraria escasamente modernizada, incapaz de generar trabajo y alimentos que mantuviesen los ya bajos niveles de vida de las generaciones anteriores. La evasión del servicio militar fue otro motivo para emigrar. Además, la información sobre las oportunidades económicas que existían en la otra orilla del Atlántico, era transmitida por familiares y amigos. El «efecto llamada», generó cadenas migratorias que tuvieron mucha importancia en las zonas de mayor flujo emigratorio. También fue relevante la acción de los agentes reclutadores al servicio de las políticas migratorias de los países latinoamericanos

La consideración de la emigración como un hecho social, y como un derecho natural de la persona vinculada al principio de libertad ${ }^{2}$, determinaría que las primeras leyes española sobre emigración, que datan de $1907^{3}$ y $1924^{4}$, nacieran con el mero objetivo de proclamar la libertad de emigración y de propiciar los desplazamientos de los españoles al extranjero ${ }^{5}$, pero esta visión liberal del fenómeno migratorio determinaría que no contemplasen medidas específicas de protección social para los españoles emigrados, una vez instalados en el

${ }^{2}$ POLO SÁNCHEZ, $M^{\text {a }}$.C.- Derechos fundamentales y libertades públicas de los trabajadores extranjeros en España, Madrid, CES, 1994, pág. 25.

${ }^{3}$ La definición legal del emigrante español se determina por primera vez en la ley de Emigración, de 21 de diciembre de 1907, atendiendo a dos condicionamientos: clase de pasaje y continente de destino; el artículo $2^{\circ}$ dice así: «serán considerados emigrantes, a los efectos de esta ley, los españoles que se propongan abandonar el territorio patrio, con pasaje retribuido o gratuito de tercera clase, o de otra, que el Consejo Superior de Emigración declare equivalente, y con destino a cualquier punto de América, Asia u Oceanía...» Quedaban excluidos los españoles que se dirigían a Argelia o a Francia, puesto que la Ley no menciona Europa ni África. Esa misma ley regula por primera vez la emigración, que se permite a cualquiera excepto a los sujetos a servicio militar o condena, y algunos con matices (menores de edad, mujeres casadas). Se exige permiso del Consejo de Ministros a la emigración de colectivos cuando estaba en peligro la posible despoblación de un territorio. Con esta Ley de Emigración se hizo la emigración ultramarina masiva de españoles a América.

${ }^{4}$ La Ley de Emigración del 20 de diciembre de 1924, considera emigrantes a los «españoles o sus familias que, por causa de trabajo, abandonen el territorio nacional para establecerse fuera de él definitiva o temporalmente. Los españoles o sus familias que se dirigían a Ultramar se reputarán siempre de emigrantes si viajan con pasaje de tercera u otra clase a ésta equiparada» (artículo $2 .^{\circ}$ ).

${ }^{5}$ El periódico madrileño "Los Lunes de EL Imparcial» de 27 de junio de 1881 describe la emigración como:»... es un sueño, un delirio, una fiebre que la medicina puede estudiar. Sus síntomas son ver en sueños un país dotado por el sol, rico en una vegetación virgen y enmarañada, donde se cuenta por miles de duros y se gana una fortuna en el tiempo en que aquí se gana, cuando se gana, una peseta. La patria aparece a sus ojos como la amante desdeñada. Ese país de oro, como la novia de una noche de mayo... ». 
país de acogida, aunque ello no impide reconocer que regularon determinadas condiciones para los emigrantes españoles ${ }^{6}$

La Guerra Civil española y la dictadura, son las causas del primer gran éxodo migratorio de españoles en el Siglo XX. A partir de 1939 comienza a producirse un éxodo de refugiados políticos. El exilio ocasionado por la Guerra Civil española y por la dictadura significó, sin duda, una pérdida para el desarrollo económico, cultural y social de España que, como contrapartida, determinó que los países que acogieron a los refugiados españoles pudieran beneficiarse con la formación académica, científica y profesional de los exiliados. ${ }^{7}$

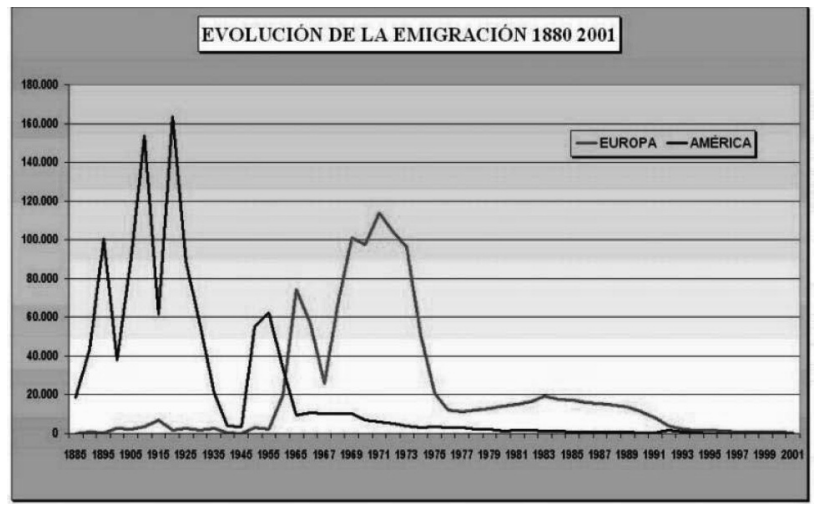

${ }^{6}$ La Ley de 1907 y el Reglamento para su aplicación, de 30 de abril de 1908, regulaban la inspección encargada de que se cumpliera la ley, y entre otras medidas, también regulaban las condiciones de los barcos y las condiciones del contrato de transporte de emigrantes, y se creaba una Caja de Emigración que recibía todos los ingresos y satisfacía todos los gastos que ocasionaba el servicio a los emigrantes.

Por su parte, la Ley de 1924 (Texto refundido de 1924, aprobado el 20 de diciembre de 1924. En este mismo día se aprobó el Reglamento para la aplicación de la Ley) regulaba la inspección para el cumplimiento de los preceptos de la ley se ejercía por los Inspectores de Emigración en las regiones españolas en las que existía emigración; en los puertos de embarque; en los buques; en los puertos de escala; y en los puertos de desembarque y en el interior de los países donde se establecieron los emigrantes españoles. Los Inspectores de Emigración, además de las atribuciones que especialmente les asignaba la Ley, debían velar por el cumplimiento del contrato de emigración y de las disposiciones relativas al aprovisionamiento y condiciones de las naves, pudiendo prohibir el embarque u ordenar la repatriación. En esta Ley se creó lo que se denominó el 'Tesoro del emigrante'. Se trataba de un fondo que se nutría con el importe de las patentes de navieros, consignatarios y oficinas de información y de pasaje de emigrantes; con el importe de las multas impuestas por infracciones de la ley, de su reglamento y de las disposiciones complementarias; con el importe del canon sobre billetes de emigrantes y de repatriados; con el producto de las publicaciones de la Dirección general; con las subvenciones y donativos que concedían las Corporaciones y particulares.

${ }^{7}$ Datos ofrecidos por el Ministerio de Trabajo e inmigración: http://www.ciudadaniaexterior.mtin.es/es/estadisticas/estadisticas.htm 
Tras el dramático éxodo político de la España republicana, la emigración económica de los españoles hacia Europa se inicia en la década de $1950^{8}$, y se trata de una emigración de carácter económico, motivada por las duras circunstancias de la posguerra que se viven en España, y atraída por las buenas perspectivas de trabajo y el mayor nivel de vida derivado del crecimiento económico existente en esos países.

Los factores que determinan este desplazamiento masivo de trabajadores al exterior en pleno régimen franquista son, por una parte, el notable incremento demográfico de España que provoca un excedente de mano de obra que las estructuras económicas, basadas en una economía rural y de escasa industrialización, no pueden absorber y, por otra, la expansión industrial y el crecimiento económico de los países europeos, pero también, el gran éxodo español coincidió con la necesidad de mano de obra en Europa, que se recuperaba de los estragos producidos por la Segunda Guerra Mundial, reconstruyendo ciudades.

Los gobernantes de la época fomentaban la emigración, pues aliviaba la escasez de trabajo y permitía ingresos en divisas para las arcas del Estado. Y es que no podemos olvidar que la emigración de la década de los años sesenta, así como la de las décadas anteriores, tuvo efectos beneficiosos, tanto para el trabajador, que tenía la posibilidad de obtener un empleo mejor remunerado y de mejorar su cualificación profesional y sus condiciones de vida, como también para el crecimiento económico de España, ya que la entrada de divisas enviadas por los emigrantes permitió sufragar parte del déficit comercial y equilibrar la balanza de pagos, facilitando las importaciones de bienes de equipo destinados a la modernización de las empresas. Esta situación contribuyó en gran medida a la expansión industrial de España en los años sesenta y setenta.

La otra cara del proceso migratorio ponía de manifiesto, junto a estos efectos beneficiosos, que la realidad de la emigración y del exilio, también implica la existencia de consecuencias negativas para los trabajadores emigrantes, los exiliados y sus familias derivadas del desarraigo social y cultural de España, y, sobre todo, de las dificultades de inserción social y laboral en el país de acogida y de los problemas

\footnotetext{
${ }^{8}$ Durante esa década el principal destino migratorio español siguieron siendo los países americanos. Pero no son los únicos: otra importante masa de trabajadores no cualificados inicia un éxodo económico hacia Europa: Francia, Alemania, Suiza, Bélgica, Países Bajos, Inglaterra... También hacia América, con cifras muy importantes: en 1950, 55.314 españoles embarcan para países del área hispana: Argentina, Uruguay, Venezuela..., y en 1955 salen para ultramar 62.237 españoles.
} 
que habían de abordar en su proyecto de retornar a España, aspectos estos últimos, que los poderes públicos españoles, en un primer momento obviaron, y sólo muy tardíamente contemplaron de una manera muy tímida.

No existían derechos y libertades en aquella España, pero, además de poder hablar de españoles de primera y de segunda, por su condición política, también existía una ciudadanía española muy dispar por razón del país en que se vivía.

\section{EL TRATAMIENTO LEGISLATIVO DE LA EMIGRACIÓN ESPAÑOLA.}

Las leyes han de seguir una evolución, cambiando y adaptándose a las necesidades de la sociedad en la que se promulgan. La legislación sobre emigración elaborada por España no ha sido una excepción, y el análisis de su contenido refleja los cambios que se han producido en este país desde la aprobación de la primera ley de emigración en 1907, hasta la Ley 40/2006 de 14 de diciembre del Estatuto de la Ciudadanía española en el Exterior (ECEE).

El concepto de emigración comenzó a aplicarse en la legislación española a partir de las Cortes de 1810-13. Por tanto, se trata de un término que ha surgido y se ha desarrollado dentro del constitucionalismo, que en sus primeros momentos concibió el derecho a emigrar como un derecho fundamental del individuo.

Las primeras leyes para la regulación de la emigración se promulgaron a partir de 1850. Durante el proceso de colonización de América, hubo diversas leyes que regularon la emigración, aunque no se usaba este término para referirse al hecho migratorio. No obstante, la emigración solía estar prohibida, bajo pena de que los bienes del emigrante fueran confiscados.

En el desarrollo de la legislación sobre emigración se pueden destacar dos grandes momentos:

El primero hace referencia al periodo entre 1907 y 1971, en el que se promulgaron las cuatro leyes de emigración que ha tenido España en el siglo XX, y que coincide con la época en la que España ha sido, fundamentalmente, un país emigrante.

El segundo se refiere al periodo entre la promulgación de la última ley de emigración y la actualidad. En este periodo el país ha pasado a ser un país receptor de inmigrantes; además, se ha producido 
un cambio fundamental en la sociedad, con la aprobación de la Constitución Española el 6 de diciembre de 1978. Por tanto, en este periodo no ha sido tan necesario regular los cauces en los que se produce la emigración, como proteger los derechos de los que emigraron, y aún hoy emigran.

Desde los años cincuenta, se vienen promulgando una serie de normas destinadas a la protección social de los españoles y españolas residentes en el extranjero. El objetivo principal de esta normativa era evitar que se rompiesen los lazos con España. Por ser la emigración un fenómeno que afecta, sobre todo, a personas en edad de trabajar, las primeras leyes sólo recogían medidas destinadas a mejorar las condiciones de trabajo y a facilitar la acogida y el alojamiento en el país de destino del trabajador y su familia. No ha sido hasta principios de los noventa, cuando se han dictado las primeras leyes con medidas específicas para los españolas residentes en el extranjero.

El 17 de julio de 1956 se aprobó una ley de emigración en la que se reconoce el carácter social de este fenómeno. Esta ley creó el Instituto Español de Emigración, que, por Decreto 1582/1974, de 19 de abril, adquiriría la condición de Entidad Gestora de la Seguridad Social. Este Instituto era el encargado de llevar a cabo la acción protectora del Estado en materia de emigración, desempeñando funciones variadas, que iban desde la información, asesoramiento y orientación en diversas materias; la concesión de créditos y ayudas, o la organización de acciones formativas y educativas ${ }^{9}$.

En su introducción, la ley de creación del Instituto Español de Emigración establece que las necesidades del momento exigían modificar la ley de 1924, vigente hasta la fecha. La importancia del movimiento emigratorio y el propósito de los países receptores de dirigirlo de acuerdo con las necesidades de su economía, hacían necesaria una gestión por parte de las autoridades encargadas de la emigración en España que garantizara a los emigrantes un contrato de trabajo a su llegada al país receptor, aunque gran parte de la emigración económica llegaba sin dicho contrato de trabajo. Se hacía necesario, por tanto, llevar a cabo una política de previsión y protección que, de manera sistemática, pusiera en relación la capacidad técnica y profesional del emigrante con las necesidades demográficas de los países

${ }^{9}$ MADRIGAL MUÑOZ, Ana (2008). «Atención a la Población Española Residente en el Extranjero Mayor de 65 años». Madrid, Portal Mayores, Informes Portal Mayores, $\mathrm{n}^{\circ}$ 82.págs. 5 y 6 [Fecha de publicación: 10/04/2008] <http://www.imsersomayores.csic.es/ documentos/documentos/madrigal/atencion-01.pdf > 
abiertos a la emigración. Es decir, el Instituto de Emigración, como organismo responsable de la gestión de la emigración, se convertía, prácticamente, en una oficina de empleo.

La Ley 93/1960, de 22 de diciembre, de Bases de Ordenación de la Emigración, y el Decreto-ley 1000/1962, de 3 de mayo, que aprueba el texto articulado de dicha Ley, elaborados durante el régimen de dictadura, ignoran la existencia de cientos de miles de exiliados en Europa e Iberoamérica, si bien es cierto que marcan un cambio de criterio en el enfoque de la corriente migratoria. Las razones de este cambio obedecen a la voluntad de regular la emigración de la población española y, al mismo tiempo, impulsarla. A resultas de ello, el fenómeno migratorio se mantendrá con un crecimiento constante hasta 1967, -fundamentalmente dirigido hacia los países europeos más desarrollados-, que había comenzado a producirse hacia 1959.

La Ley 93/1960, reconoce el derecho a emigrar de todos los españoles, si bien éste se encuentra restringido por las leyes y por las limitaciones «derivadas de la protección del emigrante y de las altas conveniencias del interés nacional» (Base primera, párrafo uno).

Esta ley se orientaba, por consiguiente, hacia la planificación de la emigración, en detrimento de la emigración espontánea de épocas anteriores, mediante operaciones que abarcaran desde una adecuada capacitación profesional del emigrante, hasta el establecimiento de relaciones laborales acordes con su capacitación. La expansión de tales actividades iba íntimamente ligada a una importante labor del Estado en el plano internacional, mediante la suscripción de Convenios y Tratados de Emigración y de Seguridad Social.

La acción protectora del Estado hacia la persona que emigra comienza desde que empieza a preparar su salida de España hasta su retorno, o cuando renuncia a su nacionalidad. Se ejerce, por tanto, allí donde se encuentre la persona que emigra y su familia. Casi toda la acción protectora contemplada en esta norma iba dirigida a conseguir el pleno empleo del emigrante y la mejora de las condiciones laborales. Otras actuaciones previstas iban encaminadas a su protección durante el viaje, a facilitar su acogida y asentamiento en el país de destino, a garantizar la asistencia religiosa por la Iglesia Católica o favorecer el retorno. También se contemplaban medidas dirigidas a la familia mientras el trabajador emigrante estaba fuera de España. A través del Instituto Español de Emigración, o en concierto con otros organismos extranjeros o la iglesia católica, el gobierno facilitaba la reagrupación familiar y, si ésta no era posible, se procuraba la satisfacción de las necesidades de la familia y, especialmente, de 
los hijos que permanecían en España, como por ejemplo, mediante la concesión de becas para la educación.

La acción del Estado, que se ejercía por medio del Instituto Español de Emigración, comprendía preferentemente planes y operaciones de emigración asistida, técnica o económicamente, por el Gobierno. Estos planes se aplicaban, fundamentalmente, a las situaciones en que el futuro emigrante estaba en paro, y para fomentar la reagrupación familiar.

Al Instituto Español de Emigración le correspondía reclutar a los emigrantes, desarrollar los procesos emigratorios y la organización y ejecución de las emigraciones colectivas y las repatriaciones extraordinarias. Por otro lado, se prohibió el reclutamiento de emigrantes no autorizados expresamente por el Ministerio de Trabajo, así como el establecimiento de agencias de emigración.

La última Ley del franquismo en materia de emigración fue la Ley 33/1971, de 21 de julio, que, si bien continúa orientada al fomento de la emigración y mantiene el silencio sobre el exilio, introduce la novedad de poder acogerse a mejores y más completos planes, operaciones y programas para facilitar el desplazamiento y el acceso al empleo en el país de acogida. Esta Ley introdujo, igualmente, ayudas de carácter social, educativo y cultural, así como medidas dirigidas a la formación profesional e integración laboral tanto para los emigrantes, como para los retornados.

La Ley 33/1971, de 21 de julio, de Emigración, se aprueba ante la complejidad que estaba adquiriendo en aquellos momentos el movimiento migratorio que, como se afirmaba en la exposición de motivos, requería medidas más flexibles. La Ley reconoce la posibilidad de acogerse a planes, operaciones y programas para facilitar el desplazamiento y el acceso al empleo en el país de acogida. Al igual que en la normativa precedente, el fin que se persigue es evitar la ruptura de los vínculos jurídicos, espirituales, culturales y familiares con España. Incluía la asistencia social del emigrante, de manera que pudiese disfrutar de los derechos laborales y de Seguridad Social en el país de destino; medidas educativas y culturales, así como para la formación profesional e integración laboral de emigrantes y retorna$\operatorname{dos}^{10}$.

${ }^{10}$ MADRIGAL MUÑOZ, Ana (2008). «Atención a la Población Española Residente en el Extranjero Mayor de 65 años». Madrid, Portal Mayores, Informes Portal Mayores, $\mathrm{n}^{\circ}$ 82.pág. 6 [Fecha de publicación:10/04/2008] <http://www.imsersomayores.csic.es/documentos/documentos/madrigal/atencion-01.pdf > 
La ley de 1971, concreta el régimen legal de la emigración en España, consagrando una serie de principios y objetivos (en buena parte continuadores de los que inspiraron la legislación durante la década de los sesenta): 1) combinar la libertad de emigrar con el derecho del Estado a dirigir, regular y controlar las corrientes migratorias, 2) regular la emigración asistida, para evitar la emigración clandestina, 3) organizar un sistema asistencial, a favor de los emigrantes, 4) crear un sistema educativo para que los hijos de los trabajadores emigrantes pudiesen recibir clases del idioma y cultura de origen de sus padres, 5) implantar, a través de un conjunto bastante disperso de normas legales, una política de apoyo al retorno y 6) establecer un mecanismo de fomento para canalizar hacia España el ahorro de los emigrantes ${ }^{11}$.

Así, el preámbulo, afirma que la legislación de emigración no puede limitarse a proclamar el derecho a emigrar para, a renglón seguido, establecer los requisitos que debe cumplir el emigrante, o cuales son las acciones y funciones que corresponden al Estado. En cambio, de acuerdo con la situación nacional e internacional, la legislación debía regular el desarrollo de operaciones y programas que facilitaran la emigración de los que deseaban abandonar el país por motivos laborales.

Por otro lado, se considera indispensable llevar a cabo todas las acciones necesarias para mantener la relación de los emigrantes con su país de origen. Para ello había que adoptar diferentes medidas dirigidas a evitar la ruptura de la unidad familiar, a través de los procedimientos de reagrupación familiar, medidas que garantizaran el mantenimiento de los derechos civiles y políticos de los emigrantes; y medidas que establecieran una adecuada red de servicios sociales para que los emigrantes y sus hijos recibieran la asistencia adecuada en temas de formación y educación.

De manera similar a como lo hacía en la legislación precedente, el Estado intervenía en todo el proceso emigratorio, es decir, en la preparación de la emigración, el viaje de ida, la estancia en el extranjero y los viajes de retorno o repatriación. El Instituto Español de Emigración se encargaba en exclusiva de gestionar y obtener directamente de los transportistas y de sus representantes la reserva de plazas y la expedición de pasajes o billetes para emigrantes, e intervenir en la fiscalización de las condiciones de seguridad, co-

\footnotetext{
${ }^{11}$ Vid. CASES, J.I.- «Protección de los emigrantes: artículo 42», en Comentarios a la Constitución española de 1978 , dirigidos por ALZAGA VILLAMIL, O. Cortes Generales. Edersa,Madrid 1996-1999. T. IV, págs. 133-164.
} 
modidad e higiene de los medios de transporte. Para ello, se utilizaban con preferencia empresas españolas.

La novedad más importante se produce en materia de derechos, al establecer que el Gobierno debía encargarse de garantizar la igualdad o asimilación de los derechos laborales y de Seguridad Social de los emigrantes con respecto a los adquiridos por los ciudadanos del país de recepción. Además, el Estado debía garantizar que el hecho de emigrar no afectara negativamente a los derechos civiles y "políticos», ni a la estabilidad social o la seguridad económica de los emigrantes. Por otro lado, el Estado debía proporcionar al emigrante, y a sus familiares, las máximas oportunidades de carácter educativo, de acuerdo con lo establecido en la Ley General de Educación. El Gobierno debía velar por que los emigrantes retornasen, y participar en la obtención de un trabajo tras su regreso a España.

\section{3.- EL TRATAMIENTO CONSTITUCIONAL DE LOS DERECHOS DE LOS CIUDADANOS ESPAÑOLES EN EL EXTRANJERO Y LA LEGISLACIÓN DE DESARROLLO.}

Con la entrada en vigor de la Constitución española de 1978 nos encontramos con un hecho incuestionable, herencia de nuestra emigración y de nuestro exilio: la existencia de más de un millón y medio de españoles y sus descendientes residiendo en el extranjero. Estos españoles, por su condición y características peculiares, exigen un tratamiento específico por parte del Estado que permita, en cumplimiento del artículo 14 de la Constitución Española de 1978, garantizar a los españoles residentes en el exterior el ejercicio de los derechos y deberes constitucionales en condiciones de igualdad con los residentes en España, con el compromiso de los poderes públicos de adoptar las medidas necesarias para remover los obstáculos que impidan hacerlos reales y efectivos.

El tratamiento constitucional de los derechos de los ciudadanos españoles en el extranjero, tiene como punto de partida, de manera indudable, el artículo $14 \mathrm{CE}$ que proclama la igualdad de los españoles, sin posible discriminación por razón, entre otras circunstancias, del lugar de residencia, y, por ello, debemos de afirmar que parecería obvio cerrar este estudio afirmando que los ciudadanos españoles en el extranjero son titulares de todos los derechos que la Constitución proclama para aquellos que residimos en territorio del Estado, sin embargo, por sus características peculiares, los emigrantes exigirían un tratamiento específicamente reforzado en materia de derechos. 
Como ha manifestado JIMENEZ CAMPO ${ }^{12}$, la igualdad ha sido situada por los constituyentes como una de las invocaciones fundantes de todo el edificio de la Constitución, constituye una pauta de legitimación del orden jurídico en su conjunto y debe de presentarse como elemento de interpretación para el entendimiento de sus diversas concreciones.

La igualdad que proclama el artículo 14 es la igualdad que se realiza predominantemente en el plano del Derecho y de los derechos y deberes jurídicos y como principio constitucional, su incidencia en el ámbito de los derechos y libertades es mucho mayor, convirtiéndose en un auténtico parámetro del control de constitucionalidad y configurándose como un límite a la acción de los poderes públicos ${ }^{13}$. La igualdad que el artículo 14 contempla como derecho, trasciende esta consideración, puesto que constituye un principio constitucional que inspira todo el sistema de derechos y libertades ${ }^{14}$.

Pero junto al derecho a la igualdad, podemos encontrar en la Constitución otras manifestaciones de la igualdad que se encuentran estrechamente relacionadas entre sí. Como valor superior del ordenamiento jurídico, la proclamación del artículo 1.1 no es una mera declaración constitucional sino que, como ha afirmado el Tribunal Constitucional (STC 8/1983, de18 de febrero) se proyecta con una eficacia trascendente, de modo que toda situación de desigualdad, deviene incompatible con el orden de valores que la Constitución, como Norma Suprema, proclama. Por otro lado nos situamos ante la proclamación del artículo 9.2 que defiende la igualdad material, real y efectiva, que implica un elemento transformador de la actuación estatal -igualdad sustancial- de carácter ideal, y de realización más dificultosa y que propone modelos de mayor igualdad en el plano so-

12 JIMÉNEZ CAMPO, J.- «La igualdad jurídica como límite frente al legislador» en $R E D C, \mathrm{n}^{\circ} 9,1983$, pág. 79.

${ }_{13}$ ÁLVAREZ CONDE, E.- Curso de Derecho Constitucional, Vol. I, Madrid, Técnos, $2^{\mathrm{a}}$ ed. 1996, pág. 299.

${ }^{14}$ DIEZ-PICAZO, en un voto particular formulado a la STC 7/1983 de 14 de febrero concibe la igualdad como un principio general del Derecho y como un límite a la potestad legislativa del Estado, que contiene al mismo tiempo un derecho subjetivo. En el mismo sentido, un voto particular promovido por varios Magistrados a la STC $75 / 1983$, de 3 de agosto, considera a la igualdad como un derecho subjetivo de todos los ciudadanos; un principio fundamental del Derecho que restringe de forma clara cualquier excepción y como un principio limitador de la acción de los poderes, en especial el legislador.

${ }^{15}$ RUIZ MIGUEL, A.- «La igualdad en la jurisprudencia del Tribunal Constitucional» en GARCÍA SAN MIGUEL, L (Ed).- El principio de igualdad, Madrid, DikinsonUniversidad de Alcalá, 2000, pág. 156. 
cial, económico y cultural ${ }^{15}$, y cuya conexión con la igualdad proclamada en el artículo 1.1 y la reconocida en el artículo 14 es innegable.

La igualdad cuenta con un componente prestacional que obliga a los poderes públicos, tanto a respetar su esfera, como a instrumentar una protección jurídica eficaz, y a remover los obstáculos que impidan o dificulten su plenitud ${ }^{16}$.

La igualdad adquiere así un nuevo componente, la igualdad sustantiva, real, efectiva o material, referida a los factores de hecho que determinan la posición de los sujetos. Esta igualdad material obliga a los poderes públicos a tener en cuenta la realidad y las diferencias de hecho que caracterizan a cada colectivo, en este caso los españoles residentes en el extranjero, teniendo en cuenta las desigualdades reales existentes, interviniendo para solventar las desigualdades que no se puedan corregir dando cumplimiento al mandato de la igualdad formal. Esta igualdad material, complementaria con la igualdad formal, no exige a los poderes públicos que den un trato igual o desigual cumpliendo ciertos requisitos, sino que fija como objetivo a alcanzar por los poderes públicos: la igualdad real y efectiva, bien a través de un trato igual o un trato diferente ${ }^{17}$.

Como ha mantenido el TC, el artículo 9.2 CE como fundamento de una igualdad sustancial o promocional, puede actuar como un principio matizador de la igualdad formal consagrada en el artículo $14 \mathrm{CE}$, permitiendo regulaciones cuya desigualdad formal se justifica en la promoción de la igualdad material (STC 98/1985, de 29 de julio), de forma que, de un lado, debe admitirse como constitucional el trato distinto que pueda recaer sobre supuestos de hecho que fueran desiguales en su propia naturaleza, cuando su función contribuya al restablecimiento de la igualdad real a través de un diferente régimen jurídico impuesto, precisamente para hacer posible el valor igualdad (STC 14/1983), y de otro que, desde la perspectiva del artículo 9.2 $\mathrm{CE}$, de promoción de las condiciones de igualdad, no se considere discriminatorio que, a fin de promover una efectiva y real igualdad, los poderes públicos puedan adoptar medidas de acción positiva frente a determinadas discriminaciones (STC 3/1992, de 13 de enero).

${ }^{16}$ FREIXES SAN JUAN, T y REMOTI CARBONELL, C.- El derecho a a la libertad personal. Análisis de la Constitución, de legislación, de Tratados Internacionales y jurisprudencia, Barcelona, PPU, 1993, pág. XXXI.

${ }^{17}$ SALVADOR MARTÍNEZ, M ${ }^{\mathrm{a}}$-- «La igualdad», en Dogmática y Práctica de los derechos fundamentales, SÁNCHEZ GONZÁLEZ, S. (Coord.). Valencia, Tirant lo Blanch, 2006, págs. 102 y 103. 
El artículo 9.2, como ha indicado el TC (STC 53/1985, de 11 de abril), implica una obligación positiva para los poderes públicos en aras a dar efectividad a los derechos y libertades, promoviendo las condiciones necesarias, lo que determina la necesidad de creación de toda una serie de condiciones jurídicas, sociales y económicas que hagan posible el más pleno, real y efectivo ejercicio de los derechos y libertades por los ciudadanos, y que afecta directamente a los españoles que residen en el extranjero que han sufrido, durante largo tiempo, una situación de desigualdad respecto a los residentes en territorio nacional.

Los artículos relativos a la igualdad constituyen parámetros preferentes y necesarios en la proclamación de la igualdad por razón de residencia, pero no son los únicos preceptos que deben de ser contemplados, sino que, junto a ellos, habrá que acudir a otras normas constitucionales sin las cuales resultaría imposible determinar la necesaria intervención a favor de los españoles que residen en el extranjero.

La definición del Estado español como Estado social y democrático de Derecho, refleja la interacción entre Estado y sociedad, e implica el reconocimiento de derechos y libertades, no solo los derechos civiles y políticos, sino también derechos de carácter económico y sociales y la trascendencia social del ejercicio de los derechos y libertades (STC 18/1984, de 7 de febrero), toda vez que impone a los poderes públicos una actuación positiva para el ejercicio eficaz de estos derechos y libertades que eliminen los obstáculos que puedan surgir, en aras a hacerlos efectivos (STC 6/1981, de 16 de marzo).

La propia idea del Estado social de Derecho, convierte al artículo 9.2 en una norma que fundamenta el contenido y la eficacia de los derechos y libertades constitucionales y su posición en el sistema constitucional español, pero, además, también fundamenta la actuación de los poderes públicos. Los poderes públicos deberán orientar su actuación a hacer reales y efectivos los derechos y libertades reconocidos en la Constitución, de manera que la efectividad de los derechos y libertades se convierte en un deber constitucional para los poderes públicos, y de este deber constitucional se deriva, también, que los derechos y libertades hayan dejado de ser considerados, únicamente, como límites a la actuación de los poderes públicos ${ }^{18}$.

Por otra parte, en cumplimiento del artículo 42 de la Constitución, se hace preciso establecer una política integral de emigración y de re-

18 Vid. HÄBERLE, P.- «El legislador de los derechos fundamentales « en López Pina, A (ed).- La garantía constitucional de los derechos fundamentales: Alemania, España, Francia e Italia, Madrid, Cívitas_U. Complutense, 1990. 
torno para salvaguardar los derechos económicos y sociales de los emigrantes, de los exiliados y de los descendientes de ambos, y para facilitar la integración social y laboral de los retornados.

La Constitución no reconoce ni establece, expresamente, un derecho a emigrar ${ }^{19}$. La emigración, ya sea considerada como elección individual o como fenómeno social, es una consecuencia lógica del «derecho a entrar y salir libremente de España», consagrado en el artículo 19 como fundamental. Al Estado le corresponde, en cualquier caso, a) «velar especialmente por la salvaguardia de los derechos económicos y sociales de los trabajadores españoles en el extranjero» y b) «orientar su política hacia su retorno». Estas dos obligaciones, con el alcance que se les quiera dar, han de ser, ciertamente, principios rectores de la política social y económica.

Pero la garantía de la protección de la emigración, no solo deriva del artículo $42 \mathrm{CE}$, sino que el Capítulo III del Título I, reconoce una serie de principios que también deben de estar dirigidos a los ciudadanos españoles en el extranjero como elementos necesarios para la salvaguardia de sus derechos económicos y sociales. Así, el art. 40 establece la promoción de las condiciones favorables para el progreso económico y social; el pleno empleo, y el fomento de una política que garantice la formación y readaptación profesional; el art. 41 reconoce la necesidad de mantener un régimen público de Seguridad Social para todos los ciudadanos, que garantice la asistencia y prestaciones sociales suficientes ante situaciones de necesidad; el art. 43 reconoce el derecho a la protección de la salud; el art. 44 establece la promoción y la tutela del acceso a la cultura, a la que todos tenemos derecho, y el art. 50 la garantía, mediante pensiones adecuadas, de la suficiencia económica de los ciudadanos durante la tercera edad y su bienestar mediante un sistema de servicios sociales.

Aunque la doctrina ha admitido que en el Capítulo III del Título I no se otorgan derechos fundamentales, y de sus preceptos sólo se pueden extraer mandatos al legislador, pero no derechos para los ciudadanos, de acuerdo con el artículo $53 \mathrm{CE}$, los principios rectores informarán la legislación positiva, la práctica judicial y la actuación de los poderes públicos, pero sólo podrán ser alegados ante la jurisdicción ordinaria de acuerdo con lo que dispongan las leyes que los desarrollan.

${ }^{19}$ La Constitución de 1931 reconoció el derecho a emigrar, sin más sujeción que las limitaciones que la ley estableciese (art. 31) y añadió que su legislación social habría de regular, entre otras cosas, las condiciones del obrero español en el extranjero (art. 46). 
Los derechos económicos, sociales y culturales son, en su mayoría, derechos prestacionales ${ }^{20}$, es decir, derechos cuya satisfacción impide la abstención de los poderes públicos, exigiendo una acción, o deber de contenido positivo, cuya satisfacción exige la adopción de importantes decisiones políticas y presupuestarias, lo que puede llevar al constituyente a no otorgarles el grado de vinculación y validez que a otros derechos, ni la posibilidad de extraer de ellos derechos exigibles directamente, para permitir que la suerte de estos derechos corra paralela al desarrollo del Estado Social. Sin embargo los principios rectores del Capítulo III tienen naturaleza jurídica y valor constitucional. Son normas objetivas con respaldo constitucional.

Como ha mantenido el TC (STC 19/1982, de 5 de mayo), la relación existente entre el Estado social y democrático de Derecho (art. 1.1); la igualdad sustancial (art. 9.2) y los principios rectores, determina que éstos no sean normas sin contenido y obliga a tenerlos presentes en la interpretación, tanto de las restantes normas constitucionales, como de las leyes.

En cuanto principios que se pueden configurar como derechos que tienden a remover los obstáculos y diferencias entre los individuos y pretenden la igualdad, por obra del mandato contenido en el art. 9.2 CE, implican una especial obligación para los poderes públicos, y se deben orientar a los grupos más desprotegidos, entre las que se encuentran los españoles residentes en el extranjero, y contribuyen a la integración social de los mismos, elemento básico en una adecuada política de protección integral y retorno, puesto que tienden a considerar al ser humano en su específica situación social.

De acuerdo con lo que dispone el art. 53.3 CE, el reconocimiento, respeto y protección de estos principios deberán informar la legislación positiva, la práctica judicial y la actuación de los poderes públicos, pero, además, habrá que tener en cuenta que estos principios, a parte de su respaldo constitucional, están reconocidos a través de Instrumentos Internacional ratificados por el Estado español, lo que implica, de un lado, que los preceptos constitucionales tendrán que ser interpretados de acuerdo con el contenido de dichos Tratados (art. 10.2), y de otro, que estos Tratados, cuando hayan sido celebrados válidamente y publicados en España oficialmente, formarán parte del ordenamiento interno (art. 96.1 $)^{21}$.

${ }^{20}$ PRIETO SANCHÍS, L.- Estudios sobre derechos fundamentales, Madrid, Debate, 1990, págs. 187 y ss.

${ }^{21}$ En cuanto a las normas internacionales que resultan de aplicación a la emigración, las más relevantes son: el artículo 13 de la Declaración Universal de los Derechos Humanos, de 1948; el Convenio 97 de la Organización Universal del Trabajo, relativo 
Todos estos principios rectores sirven para dar efectividad al Estado Social de Derecho que nuestra Constitución proclama en el art. 1.1, y que implica, no solo el reconocimiento de los derechos civiles y políticos, cuya titularidad es incuestionable para todos los españoles, con independencia de su lugar de residencia, sino también el reconocimiento de otros derechos y principios económicos, sociales y culturales, que, aunque no gocen de la misma protección, sí vinculan la actuación de los poderes públicos, y tienen una relevancia especial en la actuación del legislador. El Estado Social implica indisociablemente la idea de igualdad, y, en este sentido, la mera consideración de la igualdad como valor superior del ordenamiento jurídico implica que, aunque ningún otro precepto constitucional volviera a hacer mención expresa a ella, la igualdad debería estar siempre presente en toda regulación jurídica. Sin embargo, nuestro constituyente ha querido, además, que la igualdad sea real y efectiva, imponiendo a los poderes públicos la obligación de remover cualquier obstáculo que dificulte esta realidad y efectividad de la igualdad, de manera que se facilite la participación de todos los ciudadanos en la vida política, económica, cultural y social. Así, junto a la igualdad jurídica, el art. 9.2, implica un mandato de remoción de las situaciones de desigualdad real, transformando la actuación de los poderes públicos y encomendando al Estado que regule las condiciones básicas que garanticen la igualdad de todos los españoles ${ }^{22}$. Este deber de actuación positiva del Estado se manifiesta mediante una adecuada actuación legislativa que, en el caso que nos ocupa, haga posible la igualdad entre los ciudadanos españoles, independientemente de su lugar de residencia.

En materia de ciudadanos españoles residentes en el extranjero, la actuación legislativa del Estado democrático no ha sido especialmente prolija hasta fechas recientes. No obstante, se han dictado normas tendentes a reforzar la protección de la emigración española.

a la discriminación en materia de empleo y ocupación, de 1958; el Convenio 117 de la Organización Internacional del Trabajo, relativo a las normas y objetivos básicos de la política social, de 1968; la Carta Social Europea, de 1978; el Convenio Europeo de Trabajadores Emigrantes, de 1977 y el Convenio Europeo de Seguridad Social, de 1972. Así mismo, hay normativa comunitaria en materia de aplicación de los regímenes de seguridad social a los trabajadores por cuenta ajena, a los trabajadores por cuenta propia y a los miembros de sus familias que se desplacen en el interior de la Comunidad.

${ }^{22}$ LINDE PANIAGUA, E.- Constitucionalismo democrático (o los hombres en el centro del sistema político), Madrid, Colex, 2002, págs. 56 y 57. 
El Real Decreto 1339/1987, de 30 de enero, sobre cauces de participación institucional de los españoles residentes en el extranjero ${ }^{23}$, viene a modificar el sistema de órganos de participación establecidos en la Ley de emigración de 1971 y viene a dar cumplimiento al Real Decreto 530/1985, de 8 de abril, que prevé la existencia del Consejo General de la Emigración dentro de la estructura orgánica del Ministerio de Trabajo y Seguridad Social.

En 1993 se publica el Real Decreto 728/199324, por el que se establecen las pensiones asistenciales por ancianidad a favor de los emigrantes españoles: se trata hasta ese momento, de la medida de mayor alcance en la protección de los españoles que viven fuera de España, que garantiza a los mayores españoles del exterior el mismo nivel de vida del que disfrutan los residentes en nuestro país. Su antecedente es el artículo 7.4. de la Ley 26/1990, de 20 de diciembre, por el que se establecen en la Seguridad Social prestaciones no contributivas, en cuya virtud, «el Gobierno, en el marco de los sistemas de protección social pública, podrá establecer medidas de protección social a favor de los españoles no residentes en España, de acuerdo con las características de los países de residencia».

La Ley 4/1996, de 10 de enero, por la que se modifica la ley 7/1985, de 2 de abril, reguladora de las bases del Régimen Local en relación con el padrón municipal, establece que la Administración General del Estado confeccionará un Padrón de españoles residentes en el extranjero (PERE), a efectos del ejercicio del derecho de sufragio. Este Padrón, de acuerdo con el Reglamento de Población y demarcación Territorial de las Entidades Locales, se constituirá con los datos existentes en el registro de matrícula de cada Oficina Consular de Carrera o Sección consular de las misiones diplomáticas.

Una actuación legislativa fundamental es la que viene de la mano de la Ley 36/2002, de 8 de octubre, de modificación del Código Civil (Cc) en materia de nacionalidad. Como indica su Exposición de motivos, el encargo que contiene el artículo 42 CE cuando encomienda al Estado la misión de velar por la salvaguardia de

${ }^{23}$ El Real Decreto 2022/1997, de 26 de diciembre modifica este Real Decreto, dando nueva redacción a los artículos 1, 7,8,9,10,11 y 12 .

${ }^{24} \mathrm{La}$ Orden TAS/561/2006, de 24 de febrero, por la que se establecen las bases reguladoras de la concesión de ayudas asistenciales correspondientes a los programas de actuación a favor de los emigrantes españoles no residentes en España (publicada en el BOE el 2 de marzo de 2006) recoge la posibilidad de que las personas mayores se beneficien de las ayudas para la cobertura sanitaria. 
los derechos económicos y sociales de los trabajadores españoles en el extranjero, a la que añade la obligación de orientar su política hacia su retorno, ha dado lugar a que se entienda por el legislador que facilitar la conservación y transmisión de la nacionalidad española es, sin duda, una forma eficaz de cumplir este mandato y éste es el principal objetivo de la reforma legal.

La reforma, introduce en el artículo $20 \mathrm{Cc}$. la posibilidad de que las personas cuyo padre o madre hubiera sido originariamente español y nacido en España, puedan optar por la nacionalidad española sin límite de edad. De este modo, se da cumplida respuesta, por un lado, a la recomendación contenida en el informe publicado en el «Boletín Oficial de las Cortes Generales» el 27 de febrero de 1998, elaborado por la Subcomisión del Congreso de los Diputados, creada para el estudio de la situación de los españoles que residen en el extranjero y, por otro, a las reclamaciones que éstos han hecho llegar al Consejo de la Emigración, solicitando se superara el sistema de plazos preclusivos de opción establecidos sucesivamente por las Leyes 18/1990, 15/1993 y 29/1995.

También se modifica el artículo 24 Cc. para establecer un sistema que permitiera al que se hallara en alguno de los supuestos contemplados en el apartado 1 de ese artículo, y antes de que se cumpliera el plazo establecido en el 2, impedir la pérdida de nacionalidad que, de otra forma, se producía automáticamente al transcurrir el plazo establecido. En coherencia con todo ello, se reforma, igualmente, el artículo $25 \mathrm{Cc}$., del que además ha desaparecido el supuesto de pérdida de la nacionalidad como pena, al no contemplarse ya la misma en el Código Penal.

En esta misma línea, se suprime del artículo 26 Cc. el requisito de renunciar a la nacionalidad anterior, puesto que el mismo suponía, en la práctica, un obstáculo insuperable para la recuperación de la nacionalidad española. De esta forma, se atiende a la exigencia contenida en el punto seis de la moción aprobada por el Pleno del Congreso de los Diputados el 18 de octubre de 2000, sobre medidas para mejorar, jurídica y económicamente, la situación de los emigrantes españoles. Íntimamente relacionado con la nacionalidad española, la Ley 52/2007, de 26 de diciembre, conocida como «Ley de Memoria Histórica», reconoce la injusticia que supuso el exilio de muchos españoles durante la Guerra Civil y la Dictadura, y en su disposición adicional séptima permite la adquisición por opción de la nacionalidad española de origen a las personas cuyo padre o madre hubiera sido originariamente es- 
pañol y a los nietos de quienes perdieron o tuvieron que renunciar a la nacionalidad española como consecuencia del exilio ${ }^{25}$.

Otro paso importante en materia de emigración de españoles se produce con la aprobación de la Ley 3/2005, de 18 de marzo, por la que se reconoce una prestación económica a los ciudadanos de origen español desplazados al extranjero durante su minoría de edad, como consecuencia de la Guerra Civil, y que desarrollaron la mayor parte de su vida fuera del territorio nacional. Esta norma, por una parte, supuso un reconocimiento histórico; y por otra, dotó de protección económica y asistencia sanitaria a un colectivo concreto de españoles: los denominados «Niños de la Guerra». La Ley 3/2005, tiene por finalidad incrementar los niveles de bienestar a aquellas personas que tengan mayores niveles de necesidad ${ }^{26}$.

En diciembre de 2006 el Parlamento aprobó dos leyes de gran repercusión de cara a la ampliación de los derechos de ciudadanía: el Estatuto de la Ciudadanía española en el exterior (ECEE), del que se hablará en el epígrafe siguiente, y la conocida como «Ley de Dependencia».

La Ley 39/2006, de 14 de diciembre, de Promoción de la Autonomía Personal y Atención a las Personas en Situación de Dependencia reconoce un nuevo derecho subjetivo prestacional: la promoción de la autonomía personal y la atención de la dependencia. En relación a la ciudadanía española en el exterior, se contempla la posibilidad de que el Gobierno establezca medidas de protección a favor de los españoles no residentes en España, así como las condiciones de acceso al Sistema de Atención a la Dependencia de los emigrantes españoles retornados, previo acuerdo del Consejo Territorial, que es el órgano de cooperación del Ministerio de Trabajo y Asuntos Sociales y las Comunidades Autónomas para la puesta en marcha del Sistema.

${ }^{25}$ Además de las reformas vistas en materia de nacionalidad que contempla el Código Civil y la Ley 52/2007, de 26 de diciembre, por la que se reconocen y amplían derechos y se establecen medidas en favor de quienes padecieron persecución o violencia durante la guerra civil y la dictadura. BOE 27/12/2007, es importante la INSTRUCCIÓN de 4 de noviembre de 2008, de la Dirección General de los Registros y del Notariado, sobre el derecho de opción a la nacionalidad española establecido en la disposición adicional séptima de la Ley 52/2007, de 26 de diciembre. BOE 28/11/2008.

${ }^{26}$ No es la primera norma que se ocupa de ellas, por ejemplo, el Real Decreto 728/1993, anteriormente citado, permite que los retornados que salieron de España durante 1936 y 1942 tengan la posibilidad de percibir las pensiones asistenciales de ancianidad si se dan determinadas circunstancias 


\section{EL ESTATUTO DE LA CIUDADANÍA ESPAÑOLA EN EL EXTERIOR}

La Ley 40/2006, de 14 de diciembre, del Estatuto de la Ciudadanía española en el exterior establece el marco jurídico y los instrumentos básicos para garantizar a la ciudadanía española en el exterior el ejercicio de los derechos y deberes constitucionales, en términos de igualdad con los españoles residentes en el territorio nacional, así como reforzar los vínculos sociales, culturales, económicos y lingüísticos con España y con sus respectivas nacionalidades y comunidades de origen. El Estatuto pretende dar respuesta a las reiteradas demandas realizadas desde los distintos sectores de la emigración, del exilio y del retorno.

Con independencia de que los españoles residentes en el exterior sean titulares del resto de derechos y libertades de que somos titulares los españoles residentes en territorio nacional, la importancia del Estatuto de la Ciudadanía reside, principalmente en los siguientes aspectos:

- Esta Ley no sólo proclama por primera vez la relación de derechos de los emigrantes, sino también que los mismos tendrán el mismo contenido y alcance que los que disfrutan los españoles residentes en el territorio nacional.

- Tiene como punto de partida la idea de que la aplicación de la cláusula de Estado Social consagrada por la Constitución de 1978 ha de extenderse a todos los españoles, también a aquellos que por sus circunstancias vitales han tenido que vivir fuera del territorio nacional.

- La Ley establece, no sólo el ámbito de derechos de la ciudadanía española en el exterior, sino también, el marco de actuación y las medidas específicas que deberán desarrollarse por el Estado, y por las Comunidades Autónomas en el ámbito de sus respectivas competencias, para facilitar tanto la atención a los españoles en el exterior, como la integración social y laboral de aquellos españoles que decidan retornar a España, sin perjuicio del derecho a la libre circulación de trabajadores, ni de las competencias que ostenten las Comunidades Autónomas ni de sus leyes.

- Aunque el Estatuto se dicta al amparo del artículo 149.1.2. ${ }^{\mathrm{a}} \mathrm{de}$ la Constitución Española de 1978 que atribuye al Estado la competencia exclusiva en materia de emigración, constituye el 
marco básico para establecer el deber de cooperación entre el Estado y las Comunidades Autónomas, así como los mecanismos necesarios para la coordinación de sus actuaciones, en colaboración con la Administración Local, con los agentes sociales y con las organizaciones y asociaciones de emigrantes, exiliados y retornados.

- Recoge la política integral en materia de retorno.

- El ámbito subjetivo de aplicación de la Ley contempla la actual situación del movimiento migratorio y del retorno, superando el tradicional concepto de emigración recogido en la Ley 33/1971, de 21 de julio. Por ello, el ámbito subjetivo de aplicación del Estatuto engloba a todos los españoles en el exterior, tanto a los emigrantes y exiliados, como a los desplazados y a los familiares de ambos. Así, el art. 2 del Estatuto, establece que la Ley será de aplicación:

- A quienes ostenten la nacionalidad española y residan fuera del territorio nacional.

- A la ciudadanía española que se desplace temporalmente al exterior, incluyendo a quienes lo hagan en el ejercicio del derecho a la libre circulación.

- A los españoles de origen que retornen a España para fijar su residencia, siempre que ostenten la nacionalidad española antes del regreso.

- A los familiares de los anteriormente mencionados, entendiendo por tales el cónyuge no separado legalmente o la pareja con la que mantenga una unión análoga a la conyugal, en los términos que se determinen reglamentariamente, y los descendientes hasta el primer grado, que tengan la condición de personas con discapacidad o sean menores de 21 años o mayores de dicha edad que estén a su cargo y que dependan de ellos económicamente.

En definitiva, la importancia del Estatuto radica en la superación de la regulación anterior en materia de emigración y en constituir el primer instrumento que ofrece una visión integral del fenómeno migratorio español, en la idea de que España debe considerar a su comunidad emigrante como un auténtico capital social, y que los ciudadanos españoles en el exterior son actores imprescindibles en la construcción del futuro. 


\section{1.Ámbito de reconocimiento de derechos.}

El Título I ECEE, comprende una relación sistemática de derechos de los españoles que residen en el exterior, pero no se limita la ley a su enumeración, sino que formula medidas y mecanismos que hagan efectivo el ejercicio de los referidos derechos, y su materialización en determinadas prestaciones, dando cumplimiento, de esta forma, al mandato de igualdad real y efectiva.

Sin embargo, ha de señalarse que los derechos ya están previstos por la Constitución y por sus leyes de desarrollo, y que las prestaciones que se mencionan estaban en alguna medida establecidas. Lo novedoso es que, frente al anterior sistema de reconocimiento -en normas dispersas y de rango inferior-, con el Estatuto se pretende consolidar su ejercicio, dotándoles de una dimensión real y efectiva al elevarse el rango normativo que los ampara.

Lo que sí podemos afirmar es que el tratamiento de los derechos no sigue una sistemática adecuada, puesto que en lugar de establecer una relación en la que se distingan los derechos fundamentales de aquellos otros que no lo son, o de los principios rectores, se procede a una agrupación temática, incluyendo en cada uno de los Capítulos, derechos cuyo tratamiento debe de ser diferenciado, por razón de su protección y eficacia directa.

Así, el Capítulo I, bajo la rúbrica «derechos de participación», recoge el derecho a ser elector y elegible; la asistencia y protección de los españoles en el exterior; el derecho de petición; el derecho de acudir al Defensor del Pueblo y de información; derecho a la participación en órganos consultivos de la emigración, organizaciones sindicales y empresariales, y el derecho de asociación.

Como podemos observar, junto a derechos fundamentales, se incluyen garantías constitucionales, y se reconocen, como derechos de configuración legal, la asistencia diplomática y consular, y la participación en entidades relacionadas con la emigración. Por otro lado, este Capítulo se completa con la prohibición a los poderes públicos de adoptar ninguna medida que pueda ocasionar discriminación por razón de género, así como con la promoción de políticas de igualdad entre mujeres y hombres.

El Capítulo II, bajo la denominación de derechos sociales y prestaciones, reconoce el derecho a la protección de la salud -objetivo prioritario en la acción exterior del Estado-; derechos en materia de Seguridad Social y prestaciones por razón de necesidad, servicios sociales 
para mayores, acciones de información socio-laboral y orientación y participación en programas de formación profesional ocupacional y derechos en materia de empleo -información, orientación, formación, etc.-, dentro de una concepción amplia que abarque a todos los españoles en el exterior y retornados, especialmente aquellos considerados más vulnerables (jóvenes, mujeres y personas con discapacidad) con dificultades de inserción laboral, y ocupación.

El objetivo principal de la regulación que se hace en el Capítulo II es reconocer el compromiso de avanzar en la conservación de los derechos en la materia y de perfeccionar los mecanismos de protección existentes, sobre todo para las personas mayores, incorporando la asistencia sanitaria en sentido amplio (sanitaria, geriátrica, medicamentos, etc.) y la prestación de cuidados sanitarios en los países donde residen.

El capítulo III contempla los derechos relativos a la educación y a la cultura: derecho a la educación, homologación, convalidación y reconocimiento de títulos y estudios extranjeros, así como el acceso a las lenguas y culturas españolas. Los derechos que recoge este capítulo constituyen un todo que persigue, en definitiva, mantener los vínculos de los españoles en el exterior con España, tanto para aquellos que residen fuera, como, especialmente, para aquellos que deciden regresar.

\subsubsection{Derechos políticos y de participación.}

El Capítulo I del Título I del Estatuto reconoce los derechos de participación política y social, junto a otros derechos fundamentales de participación (derecho de petición) ${ }^{27}$; la garantía institucional del Defensor del Pueblo 28 ; el derecho de información y acceso a la información administrativa ${ }^{29}$; y eleva a la categoría de derecho la asistencia consular y

\section{${ }^{27}$ Artículo 6. Derecho de petición.}

Los españoles residentes en el exterior pueden ejercer el derecho de petición, individual o colectivamente, ante cualquier institución pública, administración o autoridad, así como ante los órganos de dirección y administración de los organismos y entidades vinculadas o dependientes de las Administraciones Públicas españolas, en los términos establecidos en la Ley Orgánica 4/2001, de 12 de noviembre, reguladora del Derecho de Petición.

${ }^{28}$ Artículo 7. Derecho a acudir al Defensor del Pueblo.

Los españoles residentes en el exterior pueden dirigirse al Defensor del Pueblo o a los órganos equivalentes de las Comunidades Autónomas invocando un interés legítimo, en las mismas condiciones que los residentes en España.

\section{${ }^{29}$ Artículo 8. Derecho de información.}

Los españoles en el extranjero tienen derecho a obtener información sobre el conjunto de las leyes y demás normas que conforman el ordenamiento jurídico español y, es- 
diplomática para los ciudadanos españoles en el extranjero, prestando especial interés al carácter prestacional del derecho fundamental a la tutela judicial efectiva ${ }^{30}$.

Sin duda, los derechos contenidos en este apartado que mayor trascendencia adquieren, son el derecho al sufragio y el derecho de asociación, como derechos políticos, y el derecho de participación social y corporativa.

\subsubsection{Derecho a ser elector y elegible.}

El artículo 23 de la Constitución establece que los ciudadanos tienen el derecho a participar en los asuntos públicos, directamente o por medio de representantes, libremente elegidos, en elecciones periódicas, por sufragio electoral. El artículo 4 del Estatuto, por su parte, reconoce que los españoles que residen en el exterior tienen derecho a ser electores y elegibles, en todos y cada uno de los comicios, en las mismas condiciones que la ciudadanía residente en el Estado español, en los términos previstos en la normativa de aplicación.

El derecho al sufragio de los ciudadanos españoles en el extranje-

pecialmente, sobre aquellas que afecten a sus derechos e intereses legítimos, para lo que la Administración Pública española contará con las nuevas tecnologías, potenciando su utilización en relación con la ciudadanía española en el exterior.

Igualmente, tienen derecho a conocer, en cualquier momento, el estado de la tramitación de los procedimientos en los que sean interesados, así como cualquier otro derecho que como ciudadano, en sus relaciones con las Administraciones Públicas, esté previsto en la normativa.

${ }^{30}$ Artículo 5. Asistencia y protección de los españoles en el exterior.

Los poderes públicos, en el ámbito de sus competencias, establecerán las medidas para que las Oficinas Consulares, Consejerías de Trabajo y Asuntos Sociales y demás dependencias de la Administración española en el exterior cuenten con los medios personales, materiales y técnicos precisos para prestar la debida asistencia, protección y asesoramiento a la ciudadanía española en el exterior.

La Administración General del Estado y la de las Comunidades Autónomas, en el ámbito de sus respectivas competencias, prestarán especial atención a aquellos que se encuentren en situaciones de necesidad y a los privados de libertad, fundamentalmente a los condenados a la pena capital o cadena perpetua, así como a la ciudadanía española que haya sido víctima de delitos de lesa humanidad en procesos de represión política.

El Estado fomentará la adopción de medidas encaminadas a reforzar la tutela judicial de los españoles en el exterior, impulsando la firma de Tratados o Convenios en materias como reconocimiento de sentencias y defensa de los penados.

Reglamentariamente, se determinarán los supuestos en que la ciudadanía española residente en el exterior que carezca de recursos económicos podrá acceder a la asistencia jurídica gratuita cuando este beneficio no exista en el país de residencia. 
ro, como manifestación primera y primaria del derecho de participación en la vida política nacional, ha sido reconocido y se viene ejerciendo, de manera generalizada, desde el principio de nuestra reciente vida democrática, y ha sido objeto de regulación legislativa.

La Ley Orgánica 5/1985, de 19 de junio, del Régimen Electoral General (LOREG), regula en sus artículos 31.2 y 32.3, todo lo relativo al censo de los españoles residentes-ausentes que viven en el extranjero. $\mathrm{El}$ art. 75.3 LOREG establece el voto por correo de los ciudadanos españoles en el extranjero en las elecciones a Diputados, Senadores, miembros de las Asambleas Legislativas de las Comunidades Autónomas y Diputados al Parlamento Europeo, y el art. 190 regula el sistema de voto por correspondencia de los residentes ausentes que vivan en el extranjero para las elecciones municipales.

Para poder votar, los residentes españoles en el extranjero, y los españoles que temporalmente se encuentren en el extranjero, deben estar inscritos en el Censo Electoral de Residentes Ausentes (CERA) que se encuentra en el Consulado español del país de residencia o estancia. Las listas del CERA estarán expuestas en las respectivas Oficinas y Secciones consulares de Embajada para su consulta y actualización de datos y presentación de reclamaciones.

Con los datos existentes en los CERA de las Oficinas o Secciones consulares correspondientes a la residencia habitual en el extranjero, se elabora el Padrón de españoles residentes en el extranjero (PERE), bajo dependencia del Instituto nacional de Estadística (INE).

El INE ha publicado, por primera vez en 2009 los datos estadísticos del PERE ${ }^{31}$ :

\begin{tabular}{|c|c|c|c|c|c|}
\hline \multicolumn{6}{|c|}{ CENSO POR COMUNIDADES } \\
\hline & $1-1-09$ & $1-12-09$ & & $1-1-09$ & $1-12-09$ \\
\hline Andalucia & 146.935 & 154.425 & Islas Baleares & 11.543 & 12.668 \\
\hline Aragón & 21.309 & 22.405 & Islas Canarias & 78.583 & 85.654 \\
\hline Asturias & 70.223 & 74.953 & Rioja (La) & 8.413 & 9.076 \\
\hline Cantabria & 20.783 & 22.435 & Madrid & 152.231 & 162.459 \\
\hline Cast.-La Mancha & 19.020 & 19.430 & Murcia & 17.546 & 18.174 \\
\hline Castilla y León & 99.766 & 104.383 & Navarra & 14.227 & 15.263 \\
\hline Cataluña & 117.243 & 124.958 & País Vasco & 43.546 & 46.510 \\
\hline C.Valenciana & 56.767 & 59.524 & Ceuta & 1.995 & 2.053 \\
\hline Extremadura & 20.194 & 20.699 & Melilla & 3.178 & 3.329 \\
\hline Galicia & 334.330 & 347.774 & TOTAL & 1.237 .832 & 1.306 .172 \\
\hline
\end{tabular}

${ }^{31} 1,5$ millones de emigrantes podrían tener derecho a voto en 2012. El 13 por ciento del cuerpo electoral de Galicia reside en el extranjero. Desde el 1 de enero hasta el 1 de di- 


\begin{tabular}{|c|c|c|c|c|c|}
\hline \multicolumn{6}{|c|}{ Provincia/ Censo a 1-01-2009 / Censo a 1-12-2009 } \\
\hline \multicolumn{2}{|c|}{ TOTAL ESPAÑA } & \multicolumn{2}{|c|}{1.237 .832} & \multicolumn{2}{|c|}{1.306 .172} \\
\hline \multicolumn{3}{|l|}{ ANDALUCIA } & Tarragona & 8.727 & 9.181 \\
\hline Almeria & 23.474 & 25.157 & TOTAL & 117.243 & 124.958 \\
\hline Cadiz & 18.089 & 18.836 & \multicolumn{3}{|l|}{ C.VALENCIANA } \\
\hline Cordoba & 13.148 & 13.489 & $\begin{array}{l}\text { CVAlENGIAru } \\
\text { Alicante }\end{array}$ & 18.856 & 19.829 \\
\hline Granada & 29,901 & 31.636 & $\begin{array}{l}\text { Alcante } \\
\text { Castellon }\end{array}$ & 4.639 & $\begin{array}{r}19.89 \\
4.867\end{array}$ \\
\hline Huelva & 4.793 & 4.992 & $\begin{array}{l}\text { Castelian } \\
\text { Valencia }\end{array}$ & 33.272 & 34.828 \\
\hline Jaén & 8.351 & 8.699 & TOTAL & 56.767 & 59.524 \\
\hline $\begin{array}{l}\text { Málaga } \\
\text { Servila }\end{array}$ & 28.730 & $\begin{array}{l}30,481 \\
21.135\end{array}$ & \multirow{2}{*}{\multicolumn{3}{|c|}{ EXTREMADURA }} \\
\hline Sevila & $\begin{array}{r}20.449 \\
146.935\end{array}$ & $\begin{array}{r}21.135 \\
154.425\end{array}$ & & & \\
\hline TOTAL & 146.935 & & Bada & 8.393 & 8.523 \\
\hline \multicolumn{3}{|l|}{ ARAGÖN } & Các & 11.801 & 12.176 \\
\hline Huesca & 4,425 & 4.684 & TOTAL & 20.194 & 20.699 \\
\hline Teruel & 3.261 & 3.406 & & & \\
\hline Zaragaza & 13.623 & 14,315 & \multicolumn{3}{|l|}{ GALICIA } \\
\hline TOTAL & 21.309 & 22.405 & \multicolumn{3}{|c|}{501} \\
\hline ASTURIAS & 70.223 & 74.953 & Lugo & 43.847 & 46.196 \\
\hline \multirow{2}{*}{ CANTABRIA } & \multirow{2}{*}{20.783} & \multirow{3}{*}{22.435} & Ouren & 74.250 & 77.28 \\
\hline & & & Pontevedra & 98.768 & 102.226 \\
\hline \multicolumn{2}{|c|}{ CASTILLA-LA MANCHA } & & TOTAL & 334.330 & 347.774 \\
\hline Ciudad Real & $\begin{array}{l}3.805 \\
3.929\end{array}$ & $\begin{array}{l}4.949 \\
3.991\end{array}$ & 1. BALEARES & 11.543 & 12.668 \\
\hline Cuenca & 2.182 & 2.189 & \multicolumn{3}{|l|}{ I. CANARIAS } \\
\hline Guadalajara & 2.024 & 2.084 & Las Paimas & 18.427 & 20.735 \\
\hline Toledo & 6.000 & 6.217 & Santa Cruz & & \\
\hline TOTAL & 19.020 & 19.430 & de Tenerite & 60.156 & 64.919 \\
\hline \multicolumn{3}{|c|}{ CASTILAY YLEON } & TOTAL & 78.583 & 85.654 \\
\hline Avila & 5.439 & 5.636 & LA RIOJA & 8.413 & 9.076 \\
\hline Burgos & $\begin{array}{r}10.382 \\
31.739\end{array}$ & $\begin{array}{l}10.994 \\
33.087\end{array}$ & MADRID & 152.231 & 162.459 \\
\hline $\begin{array}{l}\text { León } \\
\text { Palencia }\end{array}$ & $\begin{array}{r}31.739 \\
4.929\end{array}$ & $\begin{array}{r}33.087 \\
5.128\end{array}$ & MURCIA & 7.546 & 18.174 \\
\hline Salamanca & 20.715 & 21.615 & & & \\
\hline Segovia & 2.139 & 2.218 & NAVARRA & 14.227 & 15.263 \\
\hline Soria & 3.515 & 3.833 & \multicolumn{3}{|l|}{ PAIS VASCO } \\
\hline Valladolid & 8.061 & 8.346 & Alava & 3.467 & 3.754 \\
\hline Zamora & 12.847 & 13.526 & Gupircoa & 16.792 & 17.868 \\
\hline \multirow{2}{*}{\multicolumn{3}{|c|}{ TOTAL }} & Vizcaya & 23287 & 24.888 \\
\hline & & & TOTAL & 43.546 & 46.510 \\
\hline $\begin{array}{l}\text { Barcelona } \\
\text { Girona }\end{array}$ & $\begin{array}{r}89.664 \\
8,475\end{array}$ & $\begin{array}{r}95.967 \\
9.021\end{array}$ & CEUTA & 1.995 & 2.053 \\
\hline Uleida & 10.377 & 10.789 & MELILLA & 3.178 & 3.329 \\
\hline
\end{tabular}

ciembre de 2009 el Censo Electoral de Españoles Residentes en el Extranjero (más conocido como CERA) se ha incrementado en casi 69.000 nuevos inscritos -68.340- al pasar de 1.237.832 a primeros del año pasado a 1.306.172 en el último mes de 2009. Se trata del mayor incremento experimentado en los últimos años y cuya explicación más probable se deba a la aplicación de la nueva normativa de acceso a la nacionalidad. Según los datos hechos públicos por la Oficina del Censo Electoral (OCE), Galicia es la Comunidad Autónoma que cuenta con un mayor número de electores residentes en el extranjero (347.774).También llamativo ha sido la subida en el número de censados en el CERA que ha tenido la Comunidad de Madrid al pasar de 152.231 a 162.459 lo que supone un incremento en tan solo 12 meses de 10.228 nuevos electores residiendo en el extranjero. Les siguen Andalucía, con 154.425; Cataluña, con 124.958; Castilla y León, con 104.383; Islas Canarias, con 85.654; Asturias, con 74.593, y la Comunidad Valenciana, con 59.524.

Los datos por países también son significativos ya que el crecimiento del CERA se concentra en siete países del continente americano. En concreto los aumentos registrados en Argentina (16.295), Cuba (8.202), Venezuela (7.502), México (6.071), Uruguay (4.744), Brasil (3.484) y Estados Unidos (3.163) suponen 49.461 de los 68.340 nuevos electores que se incorporaron al CERA en el año 2009.

Argentina sigue siendo el país en el que reside un mayor número de ciudadanos españoles, con 289.266 registrados. Francia ocupa el segundo lugar en cuanto al número de españoles residentes, con 160.085. El tercer lugar es para Venezuela que alcanza los 133.984 residentes españoles.

(http://www.espanaexterior.com/) 
El ciudadano español residente en el extranjero que vaya a votar necesita la documentación requerida para el voto. El elector recibe la documentación de forma diferente dependiendo del proceso electoral de que se trate:

Para las elecciones municipales y las Asambleas de Ceuta y Melilla, el elector tiene que comunicar por anticipado su deseo de participar en estos procesos electorales mediante escrito dirigido a la correspondiente Delegación Provincial de la Oficina del Censo electoral del municipio en el que se tuvo la última vecindad o residencia en España. La oficina del Censo remitirá al domicilio de cada elector que lo haya solicitado la documentación precisa para votar.

Para las elecciones a Diputados, Senadores, Diputados autonómicos y Diputados al Parlamento Europeo, las Delegaciones Provinciales de la Oficina del Censo electoral remitirán de oficio, a los inscritos en el CERA, un certificado de inscripción en el Censo y el resto de la documentación electoral.

El procedimiento de voto también es diferente, según el proceso electoral de que se trate:

En las elecciones municipales y las Asambleas de Ceuta y Melilla, el elector deberá remitir su voto y el resto de la documentación electoral, exclusivamente mediante correo certificado.

En las elecciones a Diputados, Senadores, Diputados de las Asambleas de las Comunidades Autónomas, y Diputados al Parlamento Europeo, el elector puede remitir su voto por correo certificado, o acudir a la Oficina Consular o Sección Consular de la Embajada por la que figura inscrito en el CERA para depositar personalmente el sobre con su voto y el resto de la documentación electoral requerida

Si el reconocimiento del derecho al sufragio estaba regulado legislativamente, y su procedimiento adecuadamente desarrollado, lo que sí introduce el artículo 4 del Estatuto de la Ciudadanía es una serie de mandatos a los poderes públicos, al objeto de dotar a este derecho de la realidad y efectividad que exige la Constitución, y eliminar cualquier desigualdad o distorsión que pueda producirse. A estos efectos, se impone al Estado:

Fomentar los tratados internacionales necesarios para que los residentes españoles en el exterior vean reconocido el derecho a ser elector y elegible en las elecciones municipales de su lugar de residencia, bajo los criterios de reciprocidad que se establezcan en dichos tratados o en la ley. En el ámbito de la Unión Europea el Estado 
adoptará las iniciativas necesarias para que en ningún país se limiten o restrinjan estos derechos.

Promover las medidas necesarias para facilitar la incorporación de la ciudadanía española en el exterior en las listas electorales de los partidos políticos, con transparencia y publicidad de las distintas opciones políticas.

Arbitrar los mecanismos precisos para asegurar la permanente actualización del censo de los electores residentes en el exterior, actualizando el Censo de Ciudadanos Españoles en el Exterior.

Para facilitar el ejercicio del derecho de voto de los españoles residentes en el exterior, se promoverán las medidas legales tendentes a homogeneizar los procedimientos electorales para la ciudadanía española en el exterior y se habilitarán los medios materiales, técnicos y humanos precisos que posibiliten la votación en urna o a través de otro medio técnico que garantice el secreto del voto y la identidad del votante.

Para garantizar la concurrencia electoral en igualdad de todos los partidos políticos, listas electorales y coaliciones, se facilitará información actualizada por parte del Estado, así como el acceso a los medios públicos de comunicación con proyección en el exterior.

\subsubsection{Derecho de asociación.}

El movimiento asociativo desarrollado por los españoles en los países de acogida, con el objetivo fundamental de la asistencia y socorro mutuo, constituyó, desde sus inicios, un instrumento vertebrador de las comunidades de españoles en el exterior, imprescindible para canalizar y materializar las actuaciones de apoyo y atención desarrolladas por los retornados.

El derecho de asociación, es un derecho de libertad que otorga a las personas una faceta para su realización integral y efectiva y la defensa de sus intereses y desarrolla una faceta de la dignidad humana, dignidad de la que dimanan los derechos y libertades que constituyen todo el Título I de la Constitución ${ }^{32}$.

${ }^{32}$ Como ha indicado SANCHEZ AGESTA, la libertad tiene como finalidad básica permitir el pleno desarrollo y el perfeccionamiento de la persona en la vida social y tiene su raíz en la dignidad humana, correspondiendo a los poderes públicos hacer que esta libertad sea efectiva, de manera que las limitaciones que por ley se puedan establecer a los derechos y libertades públicas deben de respetar el ámbito de libertad propio y los ámbitos ajenos de libertad. SÁNCHEZ AGESTA, L.- Sistema político de la Constitución española de 1978, Madrid, Edersa, 1993, págs 121 y ss. 
El derecho de asociación es una manifestación del pluralismo político y de la libertad, proclamados como valores superiores, que se convierten en técnicas instrumentales puestas al servicio de un intercambio de ideas, la defensa de unos intereses o la publicidad de problemas o reivindicaciones. Es un derecho individual de libertad, de libertad personal, con una clara proyección social y apoyo social para su realización. Constituye, además, un derecho que está conectado a otros derechos que también son fundamentales, como la libertad de expresión e información, de manera que la negación de unos, comporta el desconocimiento de otros. Y es, también, un derecho que cumple una función estructural importante en la realización del Estado social y democrático de Derecho ${ }^{33}$.

Este derecho se constituye, por tanto, en un derecho esencial de cualquier sociedad democrática por cuanto fortalece las estructuras democráticas de la sociedad, lo que revierte en el fortalecimiento de todas las instituciones democráticas y contribuye a la presencia de la diversidad.

El Tribunal Constitucional ha venido destacando que el contenido fundamental de ese derecho se manifiesta en tres dimensiones o facetas complementarias: la libertad de creación de asociaciones y de adscripción a las ya creadas; la libertad de no asociarse y de dejar de pertenecer a las mismas; y, finalmente, la libertad de organización y funcionamiento internos sin injerencias públicas. Junto a este triple contenido, el derecho de asociación tiene también una cuarta dimensión, esta vez «ínter privatos», que garantiza un haz de facultades a los asociados, considerados individualmente, frente a las asociaciones a las que pertenezcan o en su caso a los particulares respecto de las asociaciones a las cuales pretendan incorporarse (STC 104/1999, de 14 de junio, FJ 4).

La Exposición de Motivos de la L.O 1/2002, de 22 de marzo, reguladora del derecho de asociación, manifiesta que el derecho fundamental de asociación, de antigua tradición en nuestro constitucionalismo histórico, constituye un fenómeno sociológico y político como tendencia natural de las personas y como instrumento de participación respecto al cual los poderes públicos no pueden permanecer al margen.

${ }^{33}$ En relación con el derecho de asociación, Vid. AGUIAR DE LUQUE, L. Y ELVIRA PERALES, A.- «Art. 22. El derecho de asociación» en ALZAGA VILLAAMIL, O (Dir), Comentarios a la Constitución española de 1978, Madrid, Cortes GeneralesEdersa, T.II, 1997, págs. 613 y 614. 
Como ha indicado el Comité Económico y Social de la UE en su Dictamen de 28 de enero de 1998 (recogido en la Exposición de Motivos de la L.O del Derecho de Asociación de 22 de marzo de 2002), las asociaciones son muy importantes para la conservación de la democracia, puesto que permiten a los individuos reconocerse en sus convicciones, perseguir activamente sus ideales, cumplir tareas útiles, encontrar su puesto en la sociedad, hacerse oír, ejercer alguna influencia y provocar cambios. Cuando los hombres se reúnen y se organizan, se dotan de medios más eficaces para hacer llegar su opinión sobre los diferentes problemas de la sociedad a quienes toman las decisiones políticas.

El derecho de asociación está configurado «como una de las libertades públicas capitales de la persona, al asentarse justamente como presupuesto en la libertad, viene a garantizar un ámbito de autonomía personal, y por tanto también el ejercicio con pleno poder de autodeterminación de las facultades que componen esa específica manifestación de la libertad»(STC 244/1991). La libertad de asociación, es también un componente esencial de las democracias pluralistas, pues sin ella no parece viable en nuestros días un sistema tal, del que resulta, en definitiva, uno de sus elementos estructurales como ingrediente del Estado Social de Derecho, que configura nuestra Constitución y, por su propia naturaleza, repele cualquier 'interferencia de los poderes públicos (STC 56/1995) (SSTC 173/98, de 23 de julio, FJ 8; 104/1999, de 14 de junio, FJ 3).

Para dar cumplimiento a estos principios, y a su efectividad respecto a los ciudadanos españoles residentes en el extranjero, los poderes públicos, de acuerdo con el art. 15 del Estatuto de Ciudadanía:

- Apoyarán el movimiento asociativo de los españoles en el exterior y retornados en España, fomentando especialmente aquellos centros y asociaciones que tengan por objeto la promoción socio-cultural, así como a sus estructuras federativas.

- Para garantizar la continuidad del movimiento asociativo se fomentará la participación activa de los jóvenes en las organizaciones y asociaciones de españoles en el exterior y retornados.

- Se apoyarán las asociaciones de españoles retornados en España, cuya finalidad sea la información, asesoramiento y orientación al retorno y a sus federaciones, así como aquellas iniciativas que el colectivo de emigrantes retornados estime necesarias para su integración e inserción laboral.

- Reglamentariamente se establecerá un Censo de Asociaciones y 
Centros constituidos en el exterior en el que se inscribirán aquellas que sean conformes con el reconocimiento de los derechos fundamentales y libertades que contempla la Constitución Española. Todo ello se entenderá sin perjuicio de los registros creados por las Comunidades Autónomas, en ejercicio de sus competencias, para el control y seguimiento de sus centros en el exterior y de aquellos otros que pudieran crearse en el futuro.

4.1.1.3. Derecho a la participación en los órganos consultivos de la emigración.

La emigración cuenta con una larga tradición en materia de órganos colegiados de participación. Desde que en 1888 se crearon las llamadas Juntas de Emigración hasta que en 1987 se instituyeron los actuales cauces de participación institucional de los españoles residentes en el extranjero, se han configurado diferentes órganos de participación.

La participación institucionalizada en materia de emigración se canalizó en primer término a través de la constitución de cauces en dos niveles: el local, dentro de España, con la denominación de «Juntas de Emigración» establecidas en las provincias españolas del litoral, más tarde llamados «Patronatos Locales de Emigración» o, en el exterior, en el ámbito de las demarcaciones consulares, los «Patronatos de Emigrados Españoles», y posteriormente «Juntas Consulares de Emigración»; el nacional, con participación de los diversos Departamentos con competencia en la materia, de las instituciones y de los emigrantes, con denominaciones como «Consejo Superior de la Emigración», «Junta Central de la Emigración» o, en época más reciente, «Consejo del Instituto Español de Emigración».

El Real Decreto 530/1985, de 8 de abril, por el que se determinaba la estructura orgánica básica del Ministerio de Trabajo y Seguridad Social preveía la existencia del Consejo General de Emigración. El Real Decreto 1339/1987, de 30 de octubre ${ }^{34}$, sobre cauces de participación institucional de los españoles residentes en el extranjero estableció la constitución los Consejos de Residentes Españoles, con miembros elegidos por los emigrantes, en determinadas demarcaciones consulares, y reguló el Consejo General de la Emigración con

${ }^{34}$ Modificado por el Real Decreto 2022/1997, de 26 de diciembre. 
participación de la Administración Central y Autonómica, de los emigrantes, elegidos por los Consejos de Residentes, y de las Organizaciones sindicales y empresariales.

Los Consejos de Residentes Españoles se constituyeron en todas las circunscripciones consulares en cuyas listas del Censo Electoral de Residentes Ausentes se hallen inscritos, como mínimo, 700 electores, como órgano consultivo de la respectiva Oficina Consular.

El art. 9 del Estatuto de Ciudadanía, establece que los españoles residentes en el exterior tienen derecho a participar en los asuntos que les conciernan a través de los Consejos de Residentes Españoles y del Consejo General de la Ciudadanía Española en el Exterior o de los órganos equivalentes de las Comunidades Autónomas. Asimismo tienen derecho a participar en igualdad de condiciones con el resto de los españoles en los órganos existentes. Los españoles residentes en el exterior podrán ser electores y elegibles para los órganos citados en el apartado anterior, teniendo en cuenta lo establecido en las normas que regulan dichos órganos y, en lo no previsto por éstas, por lo establecido en el Título Primero, capítulos I y II, de la Ley Orgánica 5/1985, de 19 de junio, de Régimen Electoral General.

El Estatuto de la Ciudadanía redefine y establece la naturaleza y funciones de los Consejos de Residentes Españoles en sus artículos 9, 12 y 13, y este cambio en el sistema de participación, y, en menor medida, la Ley Orgánica 3/2007, de 22 de marzo, para la igualdad efectiva entre hombres y mujeres, que modifica la Ley Orgánica 5/1985, de 19 de junio, del régimen electoral general, determinó la necesaria modificación del Real Decreto 1339/1987.

El Real Decreto 1960/2009, de 18 de diciembre es la nueva norma por la que se regulan los Consejos de Residentes en el Extranjero. Los Consejos de Residentes Españoles son órganos de carácter consultivo y asesor, adscritos a las oficinas consulares de España, cuya composición, elección y régimen de funcionamiento se regulan en el Real Decreto y las disposiciones normativas de desarrollo y se constituirán, por elección, en todas las circunscripciones consulares en cuyas listas del Censo Electoral de Residentes Ausentes se hallen inscritos, como mínimo, mil doscientos electores.

De acuerdo con el art. 3 del RD 1960/2009, los Consejos de Residentes Españoles desarrollarán su actividad respecto de las siguientes materias:

a) Derechos civiles y laborales que correspondan a los españoles 
en la circunscripción consular, de conformidad con el derecho internacional.

b) Inserción de los alumnos españoles en el sistema educativo del país, actividades que al amparo de la ley local o de los tratados puedan establecerse para asegurar el mantenimiento de los vínculos culturales con España y, en general, las actividades propias de la acción educativa de España en el exterior.

c) Participación de los residentes españoles en la vida política de España, de acuerdo con la legislación española, la del país de residencia y el derecho internacional.

d) Acción social y cultural a favor de los españoles

Son funciones de los Consejos de Residentes:

- Ser cauce de comunicación entre las comunidades de españoles en el exterior y las correspondientes oficinas consulares.

- Debatir y proponer a las oficinas consulares las medidas relacionadas con su función consular que contribuyan a mejorarla en el ámbito de su circunscripción.

- Asesorar e informar a la oficina consular en los asuntos que afecten a la comunidad española.

- Difundir entre la comunidad española las medidas adoptadas por las administraciones públicas en aquellos temas que afecten a los españoles residentes en la circunscripción.

- Cooperar con la oficina consular o con otras instituciones españolas o locales para dar mayor carácter institucional a aquellas actividades que se desarrollen en beneficio de los españoles.

- Colaborar con la oficina consular en los procesos electorales de los propios Consejos de Residentes Españoles.

- Participar, en la forma que reglamentariamente se establezca, en el procedimiento de concesión de ayudas y subvenciones establecidas a favor de los españoles en el exterior.

Los Consejos de Residentes Españoles estarán compuestos por consejeros elegidos por sufragio universal, libre, directo y secreto por los españoles mayores de edad inscritos en el Censo Electoral de 
Residentes Ausentes de la circunscripción consular correspondiente. El número de consejeros será de siete en las circunscripciones consulares en que estén inscritos en el Censo Electoral de Residentes Ausentes hasta cuarenta mil españoles, de once en las que lo estén de cuarenta mil uno a ochenta mil, y de quince cuando se supere esta cifra. En el momento de la convocatoria, el jefe de la oficina consular, teniendo en cuenta los últimos datos del Censo Electoral de Residentes Ausentes correspondientes a su circunscripción consular, determinará si el Consejo de Residentes Españoles deberá contar con siete, once o quince miembros (art. 5 RD 1960/2009).

Por otra parte, en sustitución del Consejo General de la Emigración, el Estatuto crea el Consejo General de la Ciudadanía Española en el Exterior, cuyo régimen ha sido recogido en el Real Decreto 230/2008, de 15 de febrero ${ }^{35}$, por el que se regula su elección y composición ${ }^{36}$, y régimen de funcionamiento. El Consejo General de la Ciudadanía Española en el Exterior, es un órgano colegiado de carác-

${ }^{35}$ Modificado por el Real Decreto 245/2009, de 27 de febrero. Vid también la RESOLUCIÓN de 8 de septiembre de 2009, de la Dirección General de la Ciudadanía Española en el Exterior, por la que se establecen las normas para la designación de miembros del Consejo General de la Ciudadanía Española en el Exterior en el supuesto del artículo 12.2 del Real Decreto 230/2008, de 15 de febrero. BOE $16 / 09 / 2009$

${ }^{36}$ Artículo 11. Elección y nombramiento de los consejeros.

Además del Presidente, los Vicepresidentes y el Secretario, formarán parte del Consejo:

a) Los consejeros, elegidos por los Consejos de Residentes Españoles, hasta un máximo de cuarenta y tres, con la distribución que determine el Ministerio de Trabajo y Asuntos Sociales, de forma proporcional al número de españoles inscritos en el Censo Electoral de Residentes Ausentes de cada país, según los últimos datos publicados en Internet por la Oficina del Censo Electoral.

Mediante resolución del titular de la Dirección General de Emigración, se establecerán las normas para la designación de los miembros del Consejo, que deberá ser dictada en el plazo máximo de dos meses a partir de la fecha de finalización del mandato anterior.

Además de los consejeros titulares, se elegirá en cada uno de los países un número igual de consejeros suplentes.

En todo caso, para que los Consejos de Residentes Españoles de un determinado país puedan participar en ese proceso electoral será necesario que figuren inscritos en los Censos Electorales de Residentes Ausentes de ese país el número mínimo de españoles que establezca el Ministerio de Trabajo y Asuntos Sociales.

Los candidatos electos serán proclamados, como consejeros titulares y suplentes, mediante orden del Ministro de Trabajo y Asuntos Sociales.

b) Ocho consejeros, o un número de ellos que no supere el límite máximo del 20 $\%$ sobre el total de consejeros electos, de los cuales, al menos dos, corresponderán a federaciones de asociaciones de jóvenes y/o de mujeres, todos ellos a propuesta de las federaciones de asociaciones de españoles del exterior, que acrediten su representa- 
ter consultivo y asesor, adscrito al Ministerio de Trabajo, a través de la Dirección General de Emigración que, tiene por finalidad garantizar la efectividad del derecho de los españoles residentes en el exterior a participar en los asuntos que les conciernen y promover la colaboración de las Administraciones públicas en materia de atención a la ciudadanía española en el exterior y personas retornadas.

Son atribuciones del Consejo General de la Ciudadanía Española en el Exterior (art. 2 RD 230/2008):

a) Llevar a cabo o solicitar la realización de estudios sobre cuestiones y problemas que afecten a la ciudadanía española en el exterior.

b) Formular propuestas y recomendaciones en relación con los objetivos y la aplicación de los principios inspiradores de las políticas dirigidas a la ciudadanía española en el exterior.

c) Ser informado sobre la actuación de los órganos de la Administración General del Estado, competentes en materia de atención a la ciudadanía española en el exterior y personas retornadas.

tividad, en los términos que establezca el Ministerio de Trabajo y Asuntos Sociales, y en función de los siguientes criterios:

1. ${ }^{\circ}$ Población española residente en el país donde tenga su sede la entidad.

2. Número de países a cuya población representa o integra la federación o asociación.

3. ${ }^{\circ}$ Actividades desarrolladas, antigüedad, número de socios, existencia de locales propios, y cualesquiera otras circunstancias determinantes de su representatividad que se reflejen en el informe del Consejero de Trabajo y Asuntos Sociales correspondiente.

4. ${ }^{\circ}$ Equilibrio entre las radicadas en Europa y América.

Las federaciones de asociaciones representadas deberán figurar inscritas en el Censo de Asociaciones y Centros constituidos en el exterior, de la Dirección General de Emigración, previsto en el artículo 15.4 de la Ley 40/2006, de 14 de diciembre.

c) Ocho consejeros en representación de las organizaciones empresariales y sindicales más representativas.

d) Un consejero en representación de cada una de las comunidades autónomas y de las Ciudades de Ceuta y Melilla, que lo deseen, representante que será designado por estas, de conformidad con lo previsto en el artículo 10.1 de la Ley 40/2006, de 14 de diciembre, del Estatuto de la Ciudadanía Española en el Exterior.

e) Un consejero, con rango de Director General, en representación de cada uno de los Ministerios siguientes: Justicia, Economía y Hacienda, Interior y Educación y Ciencia.

2. Los consejeros, a los que se refieren los párrafos b), c), d) y e), así como sus suplentes, serán nombrados por el Ministro de Trabajo y Asuntos Sociales, a propuesta de las respectivas federaciones de asociaciones de españoles en el exterior, de las organizaciones empresariales y sindicales, de los órganos competentes de las comunidades autónomas y de las ciudades de Ceuta y Melilla, en su caso, y de los departamentos ministeriales representados. 
d) Establecer relaciones con los órganos consultivos de similar naturaleza en las comunidades autónomas, a través de la Comisión Sectorial prevista en el artículo 29.2 de la Ley 40/2006, de 14 de diciembre.

e) Conocer e informar, con carácter previo, Anteproyectos de Ley y Proyectos de Reales Decretos y de Órdenes relativos a las siguientes materias, en el ámbito de su competencia: Derechos civiles, derechos laborales y protección social, educativa y cultural, siempre que los mismos afecten directamente a los españoles en el exterior. f) Solicitar anualmente audiencia a las Comisiones competentes de las Cortes Generales para informar sobre la situación de la ciudadanía española en el exterior.

g) Aprobar el reglamento de funcionamiento del Consejo.

\subsubsection{Derechos sociales y prestaciones}

Los Capítulos II y III, del Título I del Estatuto de la Ciudadanía, reconoce los derechos sociales y culturales. Se trata del reconocimiento reforzado de los principios rectores de la política social y económica que reconoce la Constitución en el Capítulo III del Título I, excepción hecha del derecho a la educación, que la Constitución configura como un derecho fundamental.

\subsubsection{Derecho a la educación.}

El derecho a la educación constituye un derecho fundamental vinculado a la dignidad humana que tiene por objeto «el libre desarrollo de la personalidad» (art. $27 \mathrm{CE}$ ), lo que, a tenor del artículo 10.1 CE constituye uno de los fundamentos del orden político y de la paz social.

La CE atribuye genéricamente a "todos" el derecho a la educación, por considerar que como derecho del ser humano debe ser abarcado con la mayor generosidad, pero además, su finalidad: el pleno desarrollo de la personalidad; la formación en el respeto de los derechos y libertades fundamentales y en el ejercicio de la tolerancia y la libertad dentro de los principios democráticos de convivencia; la preparación para participar activamente en la vida social y cultural y la formación para la paz, la cooperación y la solidaridad entre pueblos (art. 1 L.O 2/2006, de Educación art. 
26.2 DUDH y art. 13 PIDESC), determina que en el análisis de los derechos educativos han de estar permanentemente presentes los valores constitucionales del art. 1.1; el concepto de Estado social; su proyección en el art. 9.2 CE y en el principio de igualdad y no discriminación recogido en el art. $14 \mathrm{CE}^{37}$ y la obligación a los poderes públicos de "garantizar el derecho de todos a la educación» que impone el art. 27.5 CE.

Como ha indicado el TC, (STC 86/1985, de 10 de julio), el derecho de todos a la educación, incorpora, junto a su contenido primario de derecho de libertad, una dimensión prestacional, en cuya virtud los poderes públicos habrán de procurar la efectividad de tal derecho. Al servicio de tal acción prestacional de los poderes públicos se hallan los instrumentos de planificación y promoción, así como el mandato del establecimiento de las correspondientes ayudas.

De las disposiciones constitucionales relativas al derecho a la educación, interpretadas de conformidad con la Declaración Universal de Derechos Humanos y los Tratados y acuerdos internacionales, se deduce que el contenido constitucionalmente garantizado, corresponde a «todos», independientemente de su residencia ${ }^{38}$.

Lo que establece el Estatuto de la Ciudadanía, ante la imposibilidad de escolarizar en España, por residir fuera de su territorio, a los ciudadanos españoles residentes en el extranjero, es una serie de medidas encaminadas a dar realidad y efectividad al derecho a la educación en el país de acogida, o favorecer el acceso al sistema educativo español, de acuerdo con los mecanismos que lo permitan y el establecimiento de ayudas, becas y subvenciones.

Así, el Estatuto de la Ciudadanía establece en sus artículos 23, 24 y 25 la obligación de los poderes públicos de:

- Promover medidas que favorezcan el acceso a la educación, en sus distintos niveles, en su país de residencia a través de los medios que se estimen adecuados39, con el fin de que los es-

${ }^{37}$ FERNÁNDEZ-MIRANDA CAMPOAMOR, A Y SÁNCHEZ NAVARRO, A.J.- «Art. 27. Enseñanza» en ALZAGA VILLAMIL, O (dir) Comentarios a la ...., T. III, 1996, Op, cit, págs. 164 y ss.

${ }^{38} \mathrm{El}$ acceso a los establecimientos escolares y el derecho a utilizar, en principio, los medios de instrucción que existan en un momento determinado, debe garantizarse, de acuerdo con el art. 1 CEHD, «a toda persona dependiente de la jurisdicción de un Estado contratante». Esta expresión contenida en el art. $1 \mathrm{CEDH}$, interpretada conjuntamente con el art. $14 \mathrm{CEDH}$, debe entenderse que incluye también a aquellas personas que no residen en territorio nacional. 
pañoles residentes en el exterior cuenten con una adecuada atención educativa.

- Con la finalidad de facilitar el acceso al sistema educativo español, los poderes públicos:

- Fomentarán la existencia de centros educativos públicos en el exterior mediante convenios, reconociendo el derecho a la participación de los profesores, padres y alumnos en el control y la gestión de los centros educativos españoles en el exterior, en los términos que reconozca la legislación española.

- Se fomentará la realización de estudios universitarios en España mediante la concesión de becas o la suscripción de convenios de colaboración con universidades españolas.

- Promover el acceso a las universidades no presenciales o a distancia fomentando el empleo de las nuevas tecnologías ${ }^{40}$.

- Adoptar las medidas necesarias para la simplificación y agilización de los procedimientos de homologación, convalidación y reconocimiento de títulos y estudios extranjeros, a fin de facilitar la continuidad de los estudios en España y, en su caso, la inserción en el mercado de trabajo, de acuerdo con la normativa aplicable.

- Arbitrar los mecanismos necesarios para facilitar a los descendientes de españoles residentes en el exterior el conocimiento del castellano, y adoptar, en colaboración con las Comunidades Autónomas, las medidas precisas para favorecer el conocimiento de sus lenguas cooficiales.

- Garantizar a niños y adultos españoles con discapacidad una enseñanza de la lengua y cultura españolas debidamente adaptada.

- Promover la divulgación y el conocimiento tanto de la diversidad cultural española, como del patrimonio cultural común.

${ }^{39}$ Convenio de colaboración entre el Ministerio de Trabajo y Asuntos Sociales, el Ministerio de Educación y Ciencia y el Instituto Cervantes, para la promoción educativa de los españoles residentes en el exterior, de 12 de diciembre de 2007

${ }^{40}$ Convenio entre la Dirección General de la Ciudadanía Española en el Exterior y la Universidad Nacional de Educación a Distancia (UNED) para el acceso de los españoles del exterior a la educación universitaria y de posgrado de 24 de enero de 2008. 


\subsubsection{Derechos sociales y de prestación.}

Con anterioridad hemos tenido ocasión de estudiar cómo en el Capítulo III del Título I no se reconocen derechos fundamentales, y de sus preceptos sólo se pueden extraer mandatos al legislador, pero no derechos para los ciudadanos. Los principios rectores informarán la legislación positiva, la práctica judicial y la actuación de los poderes públicos, pero sólo podrán ser alegados ante la jurisdicción ordinaria de acuerdo con lo que dispongan las leyes que los desarrollan.

Como ha indicado PRIETO SANCHIS ${ }^{41}$, los derechos económicos, sociales y culturales son, en su mayoría, derechos prestacionales, es decir, derechos cuya satisfacción implica acción o deber de contenido positivo, y cuya satisfacción exige, la adopción de importantes decisiones políticas y presupuestarias, lo que llevó al constituyente a no otorgarles el grado de vinculación y validez que a otros derechos, ni la posibilidad de extraer de ellos derechos exigibles directamente, para permitir que la suerte de estos derechos corra paralela al desarrollo del Estado Social. Sin embargo los principios rectores del Capítulo III tienen naturaleza jurídica y valor constitucional. Son normas objetivas con respaldo constitucional.

Como ha mantenido el TC (STC 19/1982, de 5 de mayo) «la relación existente entre el Estado social y democrático de Derecho (art. 1.1); la igualdad sustancial (art. 9.2) y los principios rectores, determina que éstos no sean normas sin contenido y obliga a tenerlos presentes en la interpretación tanto de las restantes normas constitucionales como de las leyes».

El TC ha manifestado que «La Seguridad Social es una institución pública garantizada constitucionalmente (...) y frente a la que los ciudadanos disponen de derechos de estricta configuración legal (SSTC 103/1983, de 22 de noviembre; 65/1987, de 21 de mayo), y en términos parecidos ha indicado que, respecto de la garantía constitucional de un régimen de pensiones adecuadas, hay que tener en cuenta «la libertad de configuración del legislador» (STC 134/1987, de 21 de julio). El art. $43 \mathrm{CE}$, por su parte, remite a la ley el establecimiento de los derechos y deberes de «todos» respecto a la protección de la salud.

Entendemos que, por ser estos derechos de configuración legal, -incluso el TC (STC 65/1987, de 21 de mayo y STC 37/1994, de 10 de fe-

${ }^{41}$ Estudios sobre..., Op. cit, págs. 187 y ss. 
brero) ha manifestado que el legislador dispone de «libertad para modular la acción protectora del sistema (de Seguridad Social), en atención a circunstancias económicas y sociales que son imperativas para la propia viabilidad y eficacia de aquél»- la ley podrá establecer aquellas medidas dirigidas a potenciar estos principios rectores que se encuentran especialmente desfavorecidos, teniendo en consideración que el régimen de la Seguridad Social, que incluiría todos los aspectos que trata el ECEE (asistencia y prestaciones; protección a la salud y pensiones), como ha indicado el TC (STC 134/1987, de 21 de julio)»deberá respetar el principio de igualdad, la prohibición de la arbitrariedad y el aseguramiento de un mínimo prestacional al menos en situación de necesidad».

Como ha indicado el art. 22 DUDH:

"Toda persona, como miembro de la sociedad, tiene derecho a la seguridad social,y a obtener mediante el esfuerzo nacional y la cooperación internacional, habida cuenta de la organización y los recursos de cada Estado, la satisfacción de los derechos económicos, sociales y culturales indispensables a su dignidad y al libre desarrollo de su personalidad».

De acuerdo con lo preceptuado por el artículo 17 del Estatuto de la Ciudadanía, los españoles residentes en el exterior tendrán derecho a la protección a la salud en términos de equiparación con las prestaciones del Sistema Nacional de Salud. El Estado promoverá una atención integral de la salud, atendiendo con carácter prioritario a los mayores y dependientes, en igualdad con los mayores y dependientes que viven en España.

Para dar cumplimiento al mandato legal de equiparación entre españoles, residentes o no, en territorio nacional, y en cuanto derecho de prestación, no solo es preciso el desarrollo legislativo y/o reglamentario del precepto $^{42}$, sino que el Estado podrá suscribir convenios

${ }^{42}$ El desarrollo reglamentario en materia de asistencia sanitaria para españoles residentes en el extranjero ha sido abundante, antes y después de la aprobación del Estatuto para la Ciudadanía española residente en el extranjero:

- DECRETO 1075/1970, de 9 de abril, sobre asistencia sanitaria a los trabajadores españoles emigrantes y a los familiares de los mismos residentes en territorio nacional. BOE 15/04/1970.

- ORDEN de 10 de junio de 1970 por la que se dictan normas para la aplicación y desarrollo de lo dispuesto en el Decreto 1075/1970, de 9 de abril, sobre asistencia sanitaria de la Seguridad Social a los trabajadores españoles emigrantes y a sus familiares residentes en territorio nacional. BOE 20/06/1970.

- ORDEN de 13 de julio de 1971 sobre aplicación de beneficios de la Seguridad Social a los trabajadores españoles emigrantes dedicados a actividades maritimo-pesqueras por cuenta ajena. BOE 16/07/1971. 
preferentemente con las entidades públicas aseguradoras o prestadoras de cuidados de salud de los países donde sea necesario garantizar la efectividad del derecho a la protección de la salud. En su caso, podrá suscribir también convenios con entidades aseguradoras o prestadoras privadas, teniendo en especial consideración a las entidades o instituciones españolas en el exterior con capacidad para prestar la atención sanitaria.

El artículo 18, establece que la acción protectora de la Seguridad Social se extenderá a los españoles que se trasladen al exterior por causas de trabajo y a los familiares de los mismos en los términos establecidos en la legislación aplicable, para lo que el Estado proveerá cuanto fuese necesario para garantizar a los trabajadores españoles en el exterior, en materia de Seguridad Social, la igualdad o asimilación con los nacionales del país de recepción; el mantenimiento de derechos adquiridos, y la conservación de derechos en curso de adquisición, mediante la celebración de Tratados y Acuerdos con los Estados receptores, la ratificación de Convenios Internacionales y la adhesión a Convenios multilaterales.

El Estado velará por la conservación de los derechos en materia de Seguridad Social de los españoles residentes en el exterior a través de Convenios, Tratados o Acuerdos en materia de Seguridad Social, y, asimismo, el Estado deberá establecer fórmulas que permitan a los trabajadores que residan en el exterior y a los que decidan retornar, el abono de las cotizaciones voluntarias al Sistema de Seguridad Social, y arbitrará las fórmulas más beneficiosas para el reconocimiento a los trabajadores españoles en el exterior de las prestaciones económicas,

- RESOLUCIÓN de 25 de febrero de 2008, conjunta de la Dirección General de Emigración y de la Dirección General del Instituto Nacional de la Seguridad Social, por la que se regula el procedimiento para acceder a la asistencia sanitaria para españoles de origen retornados y para pensionistas y trabajadores por cuenta ajena españoles de origen residentes en el exterior que se desplacen temporalmente al territorio nacional. BOE 01/03/2008.

- RESOLUCIÓN de 6 de abril de 2009, conjunta de la Dirección General de Emigración y del Instituto Nacional de la Seguridad Social, por la que se modifica la de 25 de febrero de 2008, por la que se regula el procedimiento para acceder a la asistencia sanitaria para españoles de origen retornados y para pensionistas y trabajadores por cuenta ajena españoles de origen residentes en el exterior que se desplacen temporalmente al territorio nacional. BOE 04/05/2009.

- RESOLUCIÓN de 4 de enero de 2010, de la Dirección General de la Ciudadanía Española en el Exterior, por la que se prorroga el derecho a asistencia sanitaria para todos aquellos beneficiarios de Prestación económica por razón de necesidad a favor de los españoles residentes en el exterior que acreditasen esta condición a 31 de diciembre de 2009. 
derivadas de las cotizaciones a la Seguridad Social, y en especial a las pensiones derivadas del extinto Seguro Obligatorio de Vejez e Invalidez.

Con carácter específico, el art. 19 reconoce el derecho a percibir una prestación a los españoles residentes en el exterior que habiéndose trasladado al exterior por razones laborales, económicas o cualesquiera otras y habiendo cumplido 65 años de edad o estando incapacitados para el trabajo, se encuentren en una situación de necesidad por carecer de rentas o ingresos suficientes para cubrir sus necesidades básicas

En desarrollo de este mandato legislativo, se ha aprobado el Real Decreto 8/2008, de 11 de enero, que regula la prestación por razón de necesidad a favor de los españoles residentes en el exterior y retornados. Se da así cumplimiento al Capítulo II del Título I de la Ley que recoge derechos sociales y prestaciones, entre los que además del derecho a la protección de la salud, se introduce la prestación por razón de necesidad como un nuevo concepto que engloba la prestación económica por ancianidad, la prestación económica por incapacidad y la asistencia sanitaria.

Este Real Decreto, equipara a los cónyuges o parejas de hecho de los emigrantes al mismo nivel de protección, no quedando supeditadas a la mera condición de familiares. De esta forma, se corrige la situación de desigualdad existente hasta ahora y se garantiza el disfrute pleno de sus derechos, y tiene por finalidad establecer un mecanismo de protección que garantice el derecho a percibir una prestación a los españoles residentes en el exterior que habiéndose trasladado al exterior por razones laborales, económicas o cualesquiera otras y habiendo cumplido 65 años de edad o estando incapacitados para el trabajo, se encuentren en una situación de necesidad por carecer de recursos suficientes para cubrir sus necesidades. El importe de esta prestación vendrá determinado para cada uno de los países de forma objetiva, tomando como referencia la realidad socioeconómica del país de residencia.

A fin de promover el bienestar de los españoles mayores que residen en el exterior, el art. 20 impone a los poderes públicos la obligación de adoptar las medidas necesarias para potenciar la red de servicios sociales, fomentando la realización de actividades encaminadas a la consecución de su bienestar integral. Para ello, los poderes públicos prestarán especial apoyo, en particular económico, a aquellos centros y asociaciones de españoles en el exterior y retornados en el Estado español que cuenten con infraestructuras adecuadas para la atención de personas mayores o en situación de dependencia. 
En el marco de la regulación de la atención a la dependencia, los poderes públicos desarrollarán medidas específicas, especialmente de carácter asistencial, sanitario y farmacéutico, encaminadas a la consecución del bienestar integral de la ciudadanía española en el exterior en situación de necesidad, en aras de alcanzar la gradual asimilación a las prestaciones vigentes del Sistema para la Autonomía y Atención a la Dependencia, conforme a lo que disponga la legislación vigente.

Por último, en materia de derechos sociales, el artículo 21 regula las acciones de información socio-laboral y orientación y participación en programas de formación profesional ocupacional, y el artículo 22 los derechos en materia de empleo y ocupación. En esta materia:

- Los poderes públicos, de acuerdo con sus competencias, promoverán el desarrollo de acciones de información, orientación y asesoramiento en el exterior, a través de la red de consulados, embajadas, centros estatales y autonómicos en el mundo, asociaciones y medios de comunicación, encaminadas a facilitar la inserción socio-laboral de los españoles residentes en el exterior, a través de los correspondientes programas de ayudas o de convenios con entidades públicas o privadas.

- Los servicios públicos de empleo fomentarán la participación de los españoles residentes en el exterior y de los retornados en programas de formación profesional, a fin de facilitar su incorporación al mercado laboral o de mejorar su capacitación profesional.

- El Estado y las Comunidades Autónomas podrán promover acciones concretas o establecer acuerdos con organismos públicos o privados de los respectivos países para facilitar, la incorporación al mercado laboral de los jóvenes; de las mujeres y de las personas con discapacidad con especiales dificultades de inserción laboral,

- Los poderes públicos promoverán el acceso a la información que permita a los españoles demandantes de empleo residentes en el exterior y a los retornados, la búsqueda de empleo y la mejora de sus posibilidades de ocupación.

- El Estado velará por las condiciones del desplazamiento de profesionales y trabajadores españoles por empresas radicadas en el exterior y facilitará la contratación de trabajadores españoles residentes en el exterior. 
- El Gobierno podrá establecer visados de búsqueda de empleo dirigidos a los hijos o nietos de españoles de origen, conforme a la legislación específica de aplicación. Dichos visados tendrán un tratamiento preferencial.

\section{POLÍTICA INTEGRAL EN MATERIA DE RETORNO. ¿EL DERECHO AL RETORNO?}

Como hemos indicado con anterioridad, nuestra Constitución no reconoce el derecho a emigrar, considerándose la emigración de los españoles como una libertad que se encuentra incluida en el art. 19, y lo que nuestra Constitución reconoce es la protección integral al emigrante. La libertad de emigración está sometida a la legislación europea, cuando se emigra a Estados de la UE, y a las leyes internas de inmigración del Estado de acogida, cuando se realiza a otros países que se sitúan fuera de la órbita comunitaria.

Lo que sí cabe preguntarnos, es si nuestra Norma Suprema contempla el retorno como un derecho. Indudablemente no existe en el texto constitucional ninguna limitación al retorno, como tampoco existe proclamación expresa sobre el derecho al retorno. Lo que la Constitución prevé es la posibilidad de que el emigrante vuelva a residir en territorio nacional, retorne, y en este supuesto, se impone a los poderes públicos una actuación positiva hacia el retornado que favorezca su inclusión en una sociedad de la que ha estado ausente y en la que se puede sentir extraño.

Esta posición de inclusión del retornado, se traduce en el Estatuto de la Ciudadanía, en la adopción de una serie de medidas, que tengan un carácter integral, e integrador hacia el retornado.

Así, el artículo 26 establece que el Estado, en colaboración con las Comunidades Autónomas y las Corporaciones Locales ${ }^{43}$, promoverá una política integral para facilitar el retorno de los españoles de origen residentes en el exterior, para lo cual, los poderes públicos, coordinarán sus actuaciones para que la integración social y laboral de los españoles que retornen se realice en las condi-

${ }^{43}$ Han tenido lugar los primeros contactos y reuniones entre las principales Administraciones públicas con competencias en los temas que atañen a la atención de este colectivo tras el retorno (Esta Secretaría de Estado deInmigración e Emigración, a través de su Dirección General de la Ciudadanía Española en el Exterior, y las Comunidades Autónomas) de cara a la constitución de un mecanismo estable de coordinación de sus políticas yactuaciones, la Comisión Sectorial de Emigración. 
ciones más favorables, removiendo los obstáculos que dificulten a los españoles retornados el acceso a las prestaciones o beneficios sociales existentes ${ }^{44}$, en las mismas condiciones que los españoles residentes en España, al objeto de que la integración sea real y efectiva.

La política integral de retorno debe estar dirigida a facilitar el retorno de los españoles de origen residentes en el exterior, y, además:

- Los poderes públicos desarrollarán medidas dirigidas a facilitar la protección y el retorno de las españolas residentes en el exterior, y, en su caso, sus hijos, víctimas de situaciones de violencia de género cuando el país de residencia no ampare de manera suficiente a las víctimas de estos delitos.

- Los poderes públicos promoverán el acceso a la vivienda de los emigrantes retornados, teniendo en cuenta las necesidades específicas de este colectivo, a través de las administraciones competentes y en colaboración con las asociaciones de retornados.

La Ley 40/2006, de 14 de diciembre, del Estatuto de la ciudadanía española en el exterior, establece las políticas que deben desarrollar las Administraciones públicas españolas en relación con quienes retornan al país, y desde su aprobación se han dado importantes pasos, en lo que afecta al colectivo de retornados, en su desarrollo.

44 - LEY 38/2003, de 17 de noviembre, General de Subveniones. BOE 18/11/2003.

- REAL DECRETO 887/2006, de 21 de julio, por el que se aprueba el Reglamento de la Ley 38/2003, de 17 de noviembre, General de Subvenciones. BOE 26-07-2006.

- ORDEN TAS/874/2007, de 28 de marzo, por la que se establecen las bases reguladoras de la concesión de subvenciones, destinadas a los programas de actuación para la ciudadanía española en el exterior y los retornados. BOE de 05/04/2007.

- ORDEN TIN/2004/2008, de 26 de junio, por la que se modifica la ORDEN TAS/874/2007, de 28 de marzo, por la que se establecen las bases reguladoras de la concesión de subvenciones destinadas a los programas de actuación para la ciudadanía española en el exterior y los retornados. BOE 10/07/2008.

- ORDEN TIN/58/2009, de 21 de enero, por la que se modifica la Orden TAS/874/2007, de 28 de marzo, por la que se establecen las bases reguladoras de la concesión de subvenciones destinadas a los programas de actuación para la ciudadanía española en el exterior y los retornados BOE 27/01/2009.

- ORDEN TIN 2378/2009, de 28 de agosto, por la que se modifica la Orden TAS/874/2007, de 28 de marzo, por la que se establecen las bases reguladoras de la concesión de subvenciones destinadas a los programas de actuación para la ciudadanía española en el exterior y los retornados. 
La regulación, mediante el Real Decreto 8/2008, de 11 de enero,por el que se reconocen las prestaciones por razón de necesidad previstas en el artículo 19 del Estatuto, destinadas a que los españoles residentes en el exterior, mayores de 65 años o incapacitados para el trabajo, que carezcan de ingresos suficientes puedan optar a una renta básica para su subsistencia, se extiende, también, a los españoles retornados mayores de 65 años en aquellos casos en que cumplan los requisitos establecidos para el acceso a una pensión no contributiva del Sistema de la Seguridad Social, salvo el de periodos de residencia previos en España.

Se ha establecido un sistema de acceso a la asistencia sanitaria para quienes, tras su retorno, no tengan derecho por ningún otro concepto a esa prestación, así como para los españoles de origen retornados y pensionistas españoles de origen residentes en el exterior desplazados temporalmente al territorio nacional ${ }^{45}$.

Se ha procedido a un importante cambio en el encuadre normativo de las ayudas previstas para la atención de las situaciones de extraordinaria necesidad de los retornados, mediante la publicación del Real Decreto 1493/2007, de 12 de noviembre, que posibilita su reconocimiento en régimen de concesión directa, régimen contemplado con carácter excepcional por la Ley General de Subvenciones para supuestos en que concurran razones de interés social o humanitario, y que ha de ser regulado con ese rango. Las consecuencias prácticas de este cambio afectan sobre todo a la posibilidad de mantener abierta la convocatoria de estas ayudas con un carácter permanente y a una mayor agilidad en su gestión y reconocimiento.

En abril de 2007 inició su funcionamiento la Oficina Española del Retorno, servicio previsto también en el Estatuto, que ha tenido desde esa fecha un crecimiento constante en su actividad, tanto en la de carácter informativo como en la que afecta al establecimiento de canales de comunicación con otras Administraciones públicas o instancias implicadas en la atención de los retornados.

Se trata, en definitiva de avanzar y mejorar en la consecución del objetivo trazado para los españoles que regresan, la integración en las mejores condiciones posibles en su sociedad de origen.

\footnotetext{
${ }^{45} \mathrm{El}$ procedimiento específico para la aplicación real de este derecho se ha plasmado en la Resolución de 25 de febrero de 2008, conjunta de la Dirección General de Emigración y de la Dirección General del Instituto Nacional de la Seguridad Social.
} 


\section{BIBLIOGRAFÍA}

ALTED, A y ASENJO, A.- De la España que emigra a la España que acoge, Fundación Francisco Largo Caballero, Caja Duero, Madrid, 2006.

BORREGÓN RIBES, V.- La emigración española a América, Faro de Vigo, Vigo, 1952

DIRECCIÓN GENERAL DE EMIGRACIÓN.- Compilación de las disposiciones dictadas sobre emigración, Saez Hermanos, Madrid, 1933.

MANJON, J.R; NIETO, A.M ${ }^{\mathrm{a}}$ y SANDOVAL, P (Eds).- El Consejo General de la Emigración, Dirección General de Migraciones, Madrid, 1993

OFICINA ESPAÑOLA DEL RETORNO (Subdirección General de Normativa e Informes).- Guía del Retorno. 2008,Ministerio de Trabajo e Inmigración. Centro de Publicaciones.

PÉREZ GÁLVEZ, JUAN FRANCISCO.- Manual básico de derecho y ciudadanía española en el exterior. Ministerio de Trabajo y Asuntos Sociales. Centro de Publicaciones. 2007

PÉREZ GÁLVEZ, JUAN FRANCISCO.- Estudios jurídicos sobre la organización administrativa de la emigración: génesis del derecho emigratorio español y derecho comparado. 2007, Ministerio de Trabajo y Asuntos Sociales. Centro de Publicaciones.

RUEDA HERNANZ, G.- Españoles emigrantes en América, Arco Libros, S.L, Madrid, 2000

SÁNCHEZ ALBORNOZ, N (Comp).- Españoles hacia América. La emigración en masa, 1880-1930, Alianza Editorial, Madrid, 1988.

SÁNCHEZ ALONSO, B.- Las causas de la emigración española (18801930), Alianza Editorial, Madrid, 1995.

SOLDEVILLA ORIA, C.- El exilio español (1808-1945), Arco Libros, Madrid, 2001

VIVES, P.A, VEGA, P y OYAMBURU, J (coord.).- Historia General de la Emigración Española a Iberoamérica, Tomos I y II, Historia 16, Madrid, 1992. 